The cover (front and back) of The NIOSH Future of Work Initiative Research Agenda represents NIOSH's Future of Work Initiative priority topics across the workplace (organizational design, technological job displacement, work arrangements), work (artificial intelligence, robotics, technologies), and workforce (demographics, economic security, skills). 


\section{The NIOSH Future of Work Initiative Research Agenda}

Sara L. Tamers, Rene Pana-Cryan, Todd Ruff, Jessica M.K. Streit, Michael A. Flynn, Adele Childress, Chia-Chia Chang, Emily Novicki,

Tapas Ray, David E. Fosbroke, Charles L. Geraci

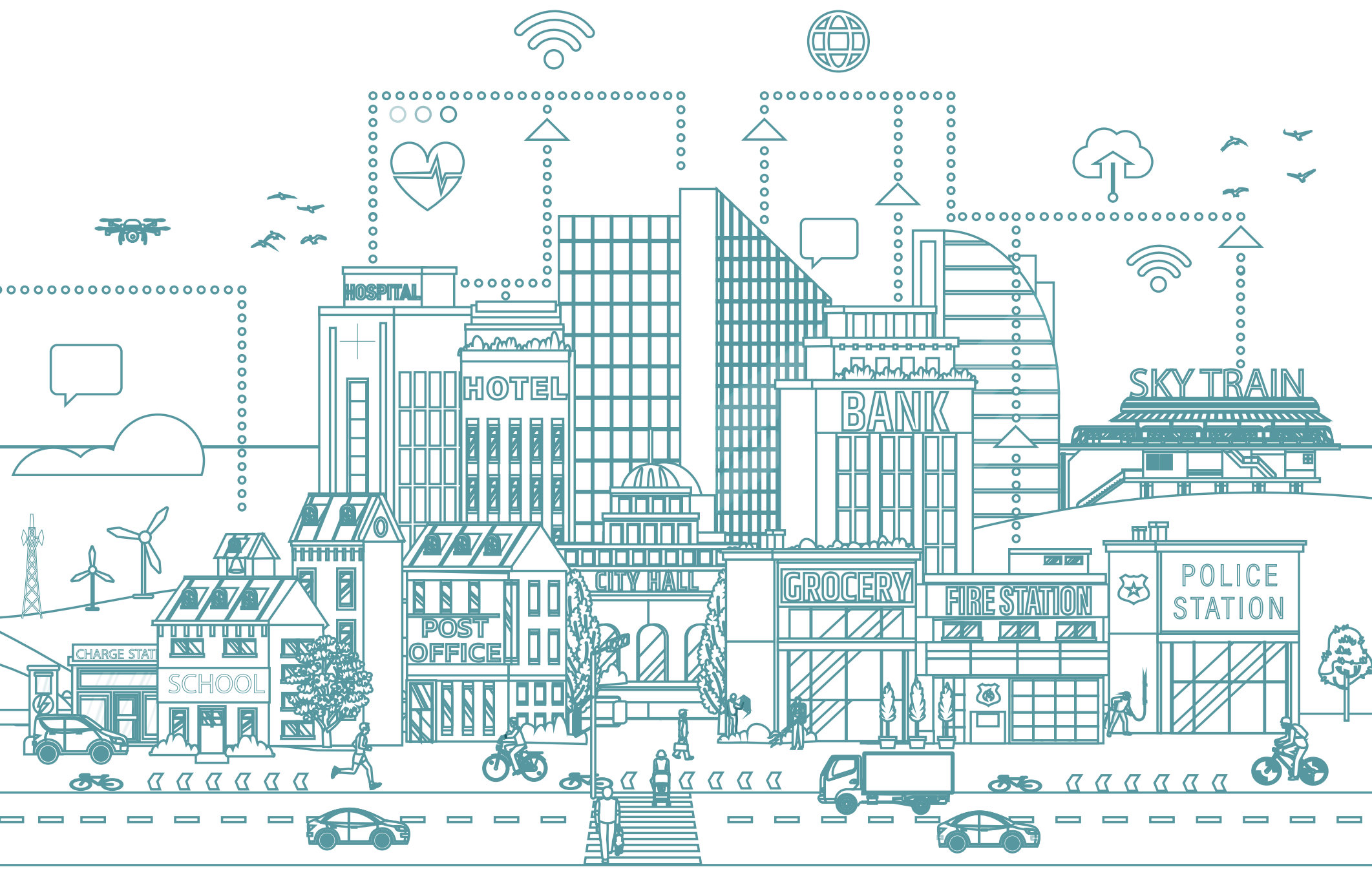

DEPARTMENT OF HEALTH AND HUMAN SERVICES

Centers for Disease Control and Prevention

National Institute of Occupational Safety and Health 
This document is in the public domain and may be freely copied or reprinted.

\section{Disclaimer}

Mention of any company or product does not constitute endorsement by the National Institute for Occupational Safety and Health, Centers for Disease Control and Prevention. In addition, citations to websites external to NIOSH do not constitute NIOSH endorsement of the sponsoring organizations or their programs or products. Furthermore, NIOSH is not responsible for the content of these websites. All web addresses referenced in this document were accessible as of the publication date.

\section{Get More Information}

Find NIOSH products and get answers to workplace safety and health questions:

1-800-CDC-INFO (1-800-232-4636) | TTY: 1-888-232-6348

CDC/NIOSH INFO: cdc.gov/info / cdc.gov/niosh

Monthly NIOSH eNews: cdc.gov/niosh/eNews

\section{Suggested Citation}

NIOSH [2021]. The NIOSH future of work initiative research agenda. By Tamers S, Pana-Cryan R, Ruff T, Streit J, Flynn M, Childress A, Chang CC, Novicki E, Ray T, Fosbroke D, Geraci C. Cincinnati, OH: U.S. Department of Health and Human Services, Centers for Disease Control and Prevention, National Institute for Occupational Safety and Health. DHHS (NIOSH) Publication No. 2022-105, https:// doi.org/10.26616/NIOSHPUB2022105.

DHHS (NIOSH) Publication No. 2022-105

DOI: https://doi.org/10.26616/NIOSHPUB2022105

December 2021 


\section{Foreword}

Technological innovations, automation, digital transformation, globalization, andmost recently-the COVID-19 pandemic have accelerated the speed at which we live and work. These and other future of work changes continue to impact workplaces and workforces in the U.S. and abroad. The challenge is navigating how best to manage the resulting complex, current, and emerging issues we collectively face.

No one knows for certain what the future holds for occupational safety and health (OSH). What is clear, however, is that it will be influenced by the choices we make today. Proactive steps are needed to ensure that the future of work favorably contributes to the safety, health, and well-being of all workers, their families, employers, communities, and the Nation.

In 2019, the National Institute for Occupational Safety and Health (NIOSH), part of the Centers for Disease Control and Prevention (CDC), launched an initiative on the future of work. Its purpose is to ready OSH and allied fields to address the work of the future and both the known and yet unknown exposures, hazards, and scenarios that arise. This research agenda provides an organized foundation from which to consider the future of work and offers concrete actions to take that will help prepare and respond.

$\mathrm{NIOSH}$ appreciates the time and effort of the expert peer and stakeholder reviewers, whose input strengthened this document.

John Howard, M.D.

Director, National Institute for Occupational

Safety and Health

Centers for Disease Control and Prevention 
This page intentionally left blank. 


\section{Table of Contents}

Foreword $\ldots \ldots \ldots \ldots \ldots \ldots \ldots \ldots \ldots \ldots \ldots \ldots \ldots \ldots \ldots$ iii

Acknowledgments........................... vii

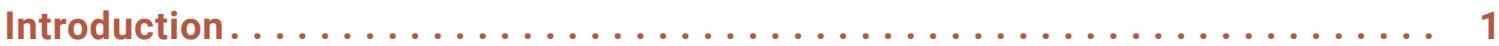

The NIOSH Future of Work Initiative $\ldots \ldots \ldots \ldots \ldots \ldots \ldots \ldots \ldots \ldots \ldots \ldots \ldots \ldots \ldots \ldots$

The NIOSH Future of Work Initiative Research Agenda . . . . . . . . . . . . 2

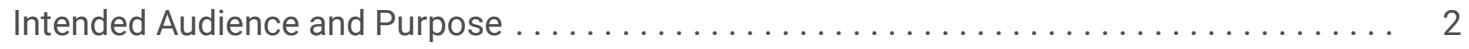

Development ....................................... 3

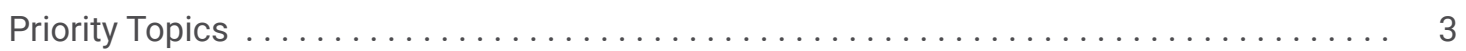

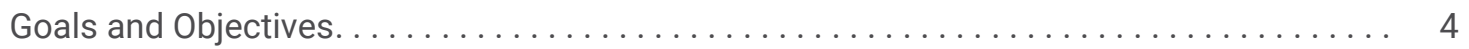

Goal 1: Improve worker safety, health, and well-being outcomes through healthier organizational design policies, programs, and practices. . . . . . . 5

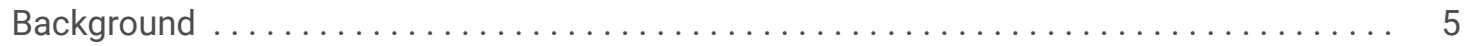

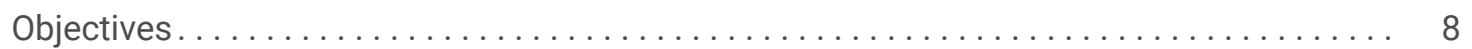

Goal 2: Determine and address worker issues related to automation, technological job displacement, and occupational polarization . . . . . . . . . 9

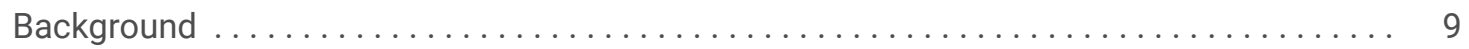

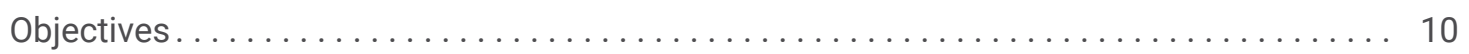

Goal 3: Identify and address the safety, health, and well-being risks for workers in different work arrangements................... 11

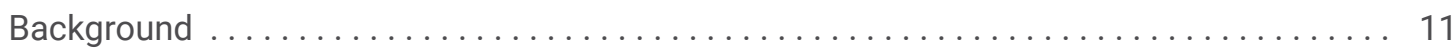

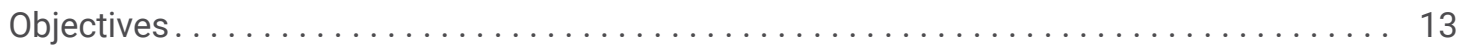

Goal 4: Minimize worker risks and maximize benefits associated with artificial intelligence application. . . . . . . . . . . . . . . . . 14

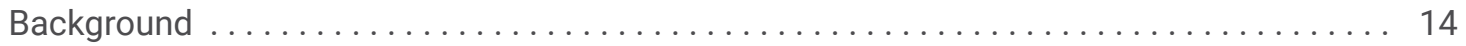

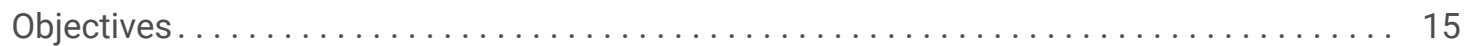

Goal 5: Mitigate worker safety and health challenges and leverage opportunities associated with robotics. . . . . . . . . . . . . . 15

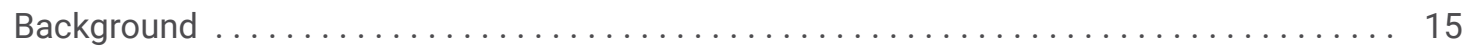

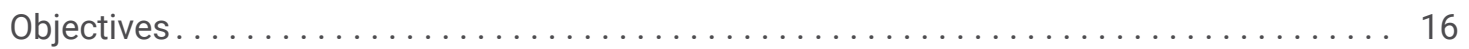

Goal 6: Evaluate the impact of innovative and emerging technologies

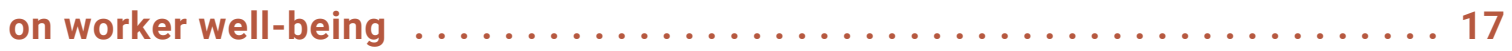

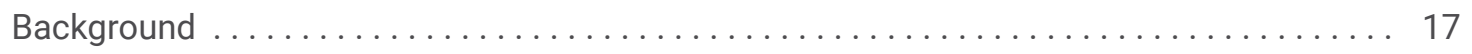

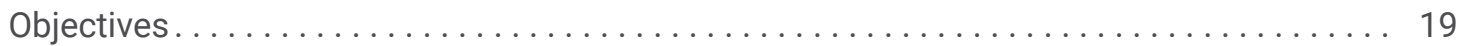

The NIOSH Future of Work Initiative Research Agenda $\quad v$ 
Goal 7: Identify, examine, and reduce the inequitable distribution of work-related risks and benefits due to demographic characteristics. . . . . . . . 19

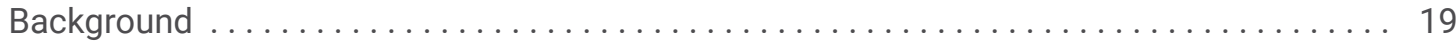

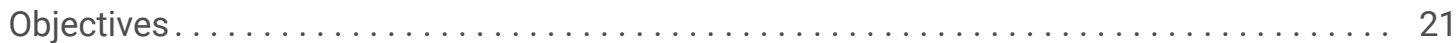

Goal 8: Reduce adverse worker safety, health, and well-being effects resulting from economic insecurity . . . . . . . . . . . . . . 22

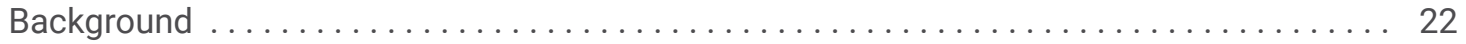

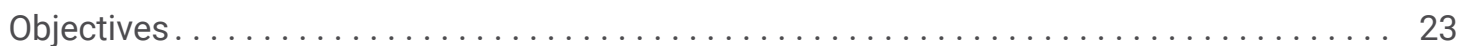

Goal 9: Assess continued education, training, and skill-building needs and approaches to improve OSH outcomes . . . . . . . . . . . . . 24

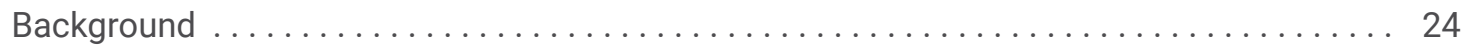

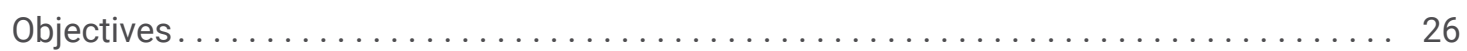

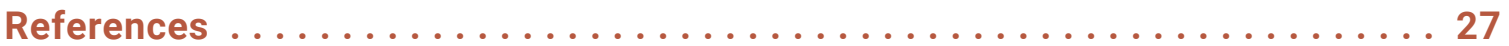




\section{Acknowledgments}

This document stems from efforts by the NIOSH Future of Work Initiative Work Group, composed of NIOSH scientists charged with identifying and addressing critical future of work research needs and advancing knowledge and practice:

- Brent Baker, PhD

- Dawn Castillo, MPH

- Chia-Chia Chang, MPH, MBA

- Adele Childress, PhD, MSPH

- Casey Chosewood, MD, MPH

- Sarah Felknor, DrPH, MS

- Michael A. Flynn, MA

- David E. Fosbroke, MSF

- Charles L. Geraci, PhD, CIH, FAIHA

- Rebecca Guerin, PhD, MA

- Scott Henn, MS

- Laura Hodson, MSPH, CIH, FAIHA

- John Howard, MD, MPH, JD, LLM, MBA

- Margaret Kitt, MD, MPH

- Emily Novicki, MA, MPH
- Rene Pana-Cryan, PhD

- Tapas Ray, PhD

- Todd Ruff, MS, PE

- Steve Sauter, PhD

- Gary Roth, PhD, MPH

- Paul Schulte, PhD

- Christina Spring, MA

- Aleksandr Stefaniak, PhD, ClH

- Jessica M.K. Streit, PhD, MS, CHES ${ }^{\circledR}$

- Naomi Swanson, PhD

- Laura Syron, PhD, MPH

- Sara L. Tamers, PhD, MPH

- CDR Sarah Unthank, MS, CIH, REHS

- Jay Vietas, PhD, MS, CIH, CSP

- Christine Whittaker, PhD 
Appreciation is also expressed to those who served as independent, external peer and stakeholder reviewers:

- Jamie Becker, LCSW-C, Laborers' Health and Safety Fund of North America

- David DeJoy, PhD, University of Georgia

- George L. Delclos, MD, MPH, PhD, University of Texas Health Science Center at Houston (UTHealth) School of Public Health

- Leslie Hammer, PhD, Oregon Institute of Occupational Health Sciences, Oregon Healthy Workforce Center, Oregon Health \& Science University

- Chris Laszcz-Davis, MS, CIH, COH, FAlHA, AIC Fellow, Environmental Quality Organization and Aluminium Consulting Engineers

- James F. McNeil, PhD, NCC, CRC, Dr. James F. McNeil Vocational Consulting Services

- Nico Pronk, PhD, HealthPartners Institute, HealthPartners 


\section{INTRODUCTION}

\section{The NIOSH Future of Work Initiative}

Even before the advent of the future of work as a focal area-cardinally represented by the Fourth Industrial Revolution [Hirschi 2018]-NIOSH developed several efforts that eventually became dedicated programs and centers [NIOSH 2021a] focused on related topics. Chiefly, these include the following:

- Nanotechnology Research Center (2004): https://www.cdc.gov/niosh/topics/nanotech/nanotechnology-research-center.html

- Occupational Health Equity Program (2005): https://www.cdc.gov/niosh/programs/ohe/default.html

- Center for Motor Vehicle Safety (2010): https://www.cdc.gov/niosh/motorvehicle/ncmvs/aboutthecenter.html

- Safe • Skilled • Ready Workforce Program (2013): https://www.cdc.gov/niosh/programs/ssrw/default.html

- Center for Direct Reading and Sensor Technologies (2014): https://www.cdc.gov/niosh/topics/drst/default.html

- Economic Research and Support Office (2014)

- Total Worker Health ${ }^{\circledR}$ Program (2014): https://www.cdc.gov/niosh/twh/default.html

- National Center for Productive Aging and Work (2015): https://www.cdc.gov/niosh/topics/productiveaging/default.html

- Healthy Work Design and Well-Being Cross-Sector Program (2016): https://www.cdc.gov/niosh/programs/hwd/default.html

- Center for Occupational Robotics Research (2017): https://www.cdc.gov/niosh/topics/robotics/default.html

Since then, ongoing and accelerating changes in the workplace, work, and workforce have continued to shape the future of work [Tamers et al. 2020]. While such developments have offered many opportunities, they have also posed challenges. As a result, increased attention has been paid to new and existing worker safety, health, and well-being issues with related implications, many of which became pronounced during the coronavirus disease 2019 (COVID-19) pandemic that has itself highlighted a necessity to focus on the future of work and the relevance of $\mathrm{OSH}$ [Sinclair et al. 2020]. Responding to these evolving needs, NIOSH introduced its Future of Work Initiative (Initiative) in 2019 [NIOSH 2021b].

The vision of the Initiative is to prepare the OSH ecosystem for a safer, healthier, and more productive future. Doing so requires that $\mathrm{OSH}$ professionals and practitioners take a closer look at relevant issues, and develop and implement new or not yet widely used safety and health mechanisms to face them [Chia et al. 2019]. 
To this end, the Initiative advocates the Total Worker Health ${ }^{\oplus}$ (TWH) approach, defined as "policies, programs, and practices that integrate protection from workrelated safety and health hazards with promotion of injury and illness-prevention efforts to advance worker well-being" [NIOSH 2021c]. Building upon traditional OSH protection programs that have primarily concentrated on ensuring work is safe and workers are protected from the harms that arise from work itself, the TWH approach is an expanded, holistic, transdisciplinary strategy that recognizes work as a social determinant of health and focuses on how the workplace and work contribute to workforce (employees' and workers') outcomes, in order to improve well-being [NIOSH 2021c]. This also includes addressing the importance of relationships between safety, health, and well-being issues that extend beyond the job and therefore impact not only workers but also their families, communities, and society.

Using the TWH framework, the Initiative is meant to be a collaborative effort of multi/transdisciplinary research and affiliated activities throughout NIOSH and with other government agencies, organizations, trade associations, labor unions or other employee representatives, and additional key partners. Its purpose is to identify novel solutions, practical approaches, and national and international partnership engagement and opportunities. More specifically, the Initiative:

- Compiles existing studies on the future of work

- Features current future of work research projects

- Promotes research on new industries, technologies, organizational designs, job arrangements, risk profiles, and risk controls

- Connects trends in workplace, work, and workforce changes to prepare for future worker safety, health, and well-being.

Doing so involves certain steps:

- Develop, examine, and address future of work priority topics

- Improve and generate sound taxonomy

- Consider current research methods and find new ones

- Offer practical, tangible solutions to safeguard workers

- Surveille, evaluate, and adjust approaches and activities, as needed.

\section{THE NIOSH FUTURE OF WORK INITIATIVE RESEARCH AGENDA}

\section{Intended Audience and Purpose}

The scope of the Initiative's Research Agenda (Agenda) extends across every NIOSH sector, cross-sector, and core and specialty program [NIOSH 2021a]. Thus, 
it involves and requires contributions from the entire NIOSH research community. The Agenda is also intended to inform the larger safety and health community about $\mathrm{NIOSH}$ future of work efforts, on behalf of the U.S. As a result, external OSH and allied associates (academics, researchers, educators, practitioners, government agencies, industry, labor unions, policymakers, and public interest groups) may be inspired to address some of the identified needs.

The Agenda's purpose is to outline predominantly research-focused directions that could also inform practice, policy, and capacity-building activities related to the Initiative. Specifically, the Agenda frames the most relevant future of work issues, as well as the safety and health needs of tomorrow's workforce, across occupations and industries. It sets goals and objectives to help NIOSH scientists identify and prioritize research-focused proposals, projects, manuscripts, products, and other activities for the current FY2019-2024 NIOSH Strategic Plan [NIOSH 2019], its next iteration, and other prospective internal and external mechanisms.

\section{Development}

The development of the Agenda began in early 2021 and reflects previous efforts of the Initiative, which included-among other tasks-reviewing hundreds of peerreviewed and other articles relevant to the future of work [Tamers et al. 2020]. Because the Agenda involves the entire NIOSH community, in addition to input received by the Initiative's Future of Work Group and independent, external peer and stakeholder reviewers, a primary task included seeking widespread input across $\mathrm{NIOSH}$. In total, 22 sector, cross-sector, and core and specialty programs [NIOSH 2021a] provided feedback on what NIOSH should prioritize in the next 5-10 years to meet future workplace, work, and workforce needs. As the future of work continues to unfold and evolve, so too must this Agenda, which will be updated and revised periodically to reflect changing priorities.

\section{Priority Topics}

One of the first steps of the Initiative was to develop a set of future of work priority topics and sub-topics to serve as a cornerstone and guiding framework for research and practice-based activities. Nine priority topics grouped into three overlapping categories reflect issues of relevance to the future of work (Figure 1). These categories and accompanying priority topics are the workplace (organizational design, technological displacement, work arrangements), work (artificial intelligence, robotics, technologies), and workforce (demographics, economic security, skills).

Figure 1 also illustrates recognized issues impacting all future of work priority topics: emergency and disaster preparedness and response, exposures and hazards, extreme weather conditions, globalization, Industry 4.0, OSH 4.0, policies, politics, resources, and social disruption. Though these overarching issues are 
not singled out here in detail, they are central and should therefore be taken into account when addressing all relevant priority topics. External factors such as working in a global community with interconnected technologies of Industry 4.0 come with influence and competitiveness considerations employers must heed; extreme weather conditions (to include natural disasters and resultant infectious disease reservoirs) have shifting demographics, workforce movement, and geographical implications; and emergency and disaster preparedness and response (such as the COVID-19 pandemic) are central to prevention, management, communication, and planning efforts (at all levels, including organizational) that impact workers' safety, health, and well-being and next level OSH strategies.

\section{CDC/NIOSH Future of Work Initiative Priority Topics}

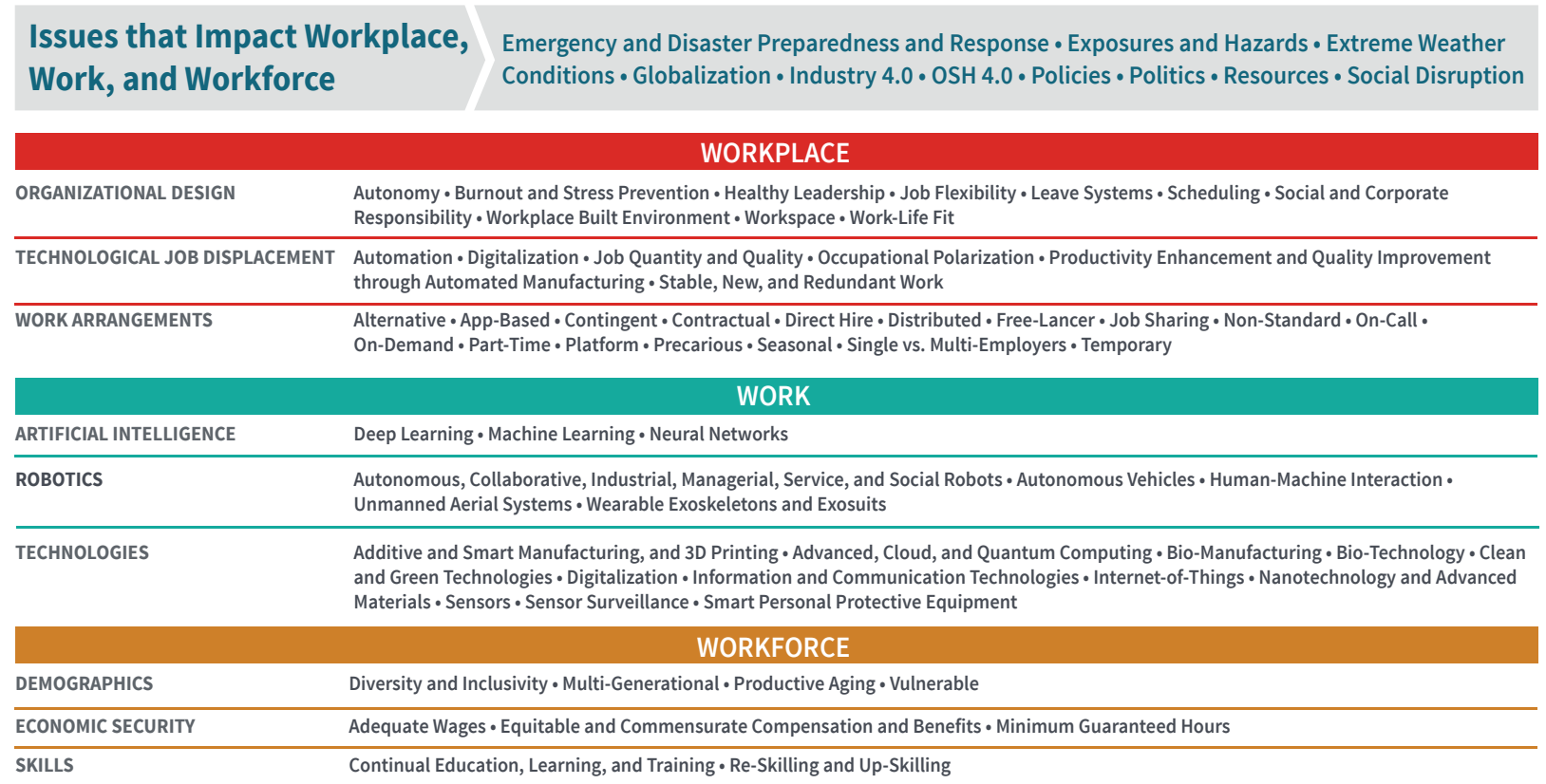

Figure 1. Priority Topics and Sub-topics of the NIOSH Future of Work Initiative

\section{Goals and Objectives}

The Initiative's future of work priority topics became the basis of its foundational paper [Tamers et al. 2020] and this Agenda. Although goals and objectives are parsed out separately, the Initiative encourages integration of areas of future of work that have traditionally been separated from each other but are intricately linked. Certain portions of the Agenda are applicable to most if not all occupations and industries, while others have more relevance to some. Additionally, even though the objectives within each goal were prioritized as ones to address at this time, they may shift in importance and urgency, while new ones will likely emerge. Therefore, it is expected that each NIOSH sector, cross-sector, and core and specialty program [NIOSH 2021a] will prioritize and adjust them further to meet the specific and changing needs of the working populations they serve. 
What's more, several goals and objectives may benefit from applying future of work tools such as strategic foresight and scanning [Hines et al. 2015] to monitor and forecast the emergence and trajectories of key issues and trends [Schulte et al. 2020, Streit et al. 2021], and by employing relevant methods like systems thinking models to help determine how NIOSH can use and communicate research findings. Such steps will contribute to updating the focus of the Agenda to highlight the latest future of workplace, work, and workforce safety, health, and well-being needs.

\section{Goal 1: Improve worker safety, health, and well-being outcomes through healthier organizational design policies, programs, and practices}

\section{Background}

Over the past several decades, technological and other developments have dramatically altered organizational design [Eurofound 2018], which encompasses and impacts the overall context in which work is performed. Perhaps most notably, job flexibility in the form of telework, remote work, and virtual work has become more accepted and, at times, vital to maintain and foster organizational efforts. For example, the COVID-19 pandemic forced many employers across industries to leverage job flexibility options so that their workforce could remain safe and operational [Brenan 2020]. This trend has led to many studies on the subject, with a leading one estimating that at least $16 \%$ of employees will continue to regularly work from home after the COVID-19 pandemic [Bartik et al. 2020]. This suggests that the utilization of alternative worksites may become a key piece of the future of work's "new normal."

Indeed, this time in history, which has led to more workers leaving their jobs than at any other point in almost a century (referred to as the "Great Resignation") [McFall 2021], has caused many employers to rethink their views on job flexibility and work location options, the need for physical worksites, as well as the facilitation (or not) of work-life fit. Of particular consideration is the feasibility (that is, whether a job is amenable to flexibility or bound by place and time) and quality of telework, remote work, and virtual work, which depend on various factors. These factors include job type, availability of dedicated home space, overlap between work and care-giving responsibilities, and whether employers believe they benefit or not from greater application of these options [Kossek et al. 2018].

Regardless of whether workers perform their jobs from a central facility, mobile site, or home office, it is well-established that the physical work environment influences both worker well-being and organizational performance [Toch et al. 2014, Ray et al. 2021]. Access to hazard-free worksites, personal protective equipment (PPE), and 
ergonomically designed workstations and work tools will remain critical. No matter the location, it is unclear how organizations will provide, evaluate, and monitor safe and healthy working environments as the concept of the workplace evolves. There is evidence, for instance, that even well before the COVID-19 pandemic, home offices were often configured without employer guidance [Ellison 2012], which can result in injuries with workers' compensation and legal implications.

In addition, there are known physical and psychological health benefits associated with working in a green building that offers smart ventilation controls, automated safety mechanisms and controls, sit-stand workstations, healthy cafeteria options, and employer-sponsored exercise programs and equipment [Kahn-Marshall et al. 2012, Pronk et al. 2012, Neuhaus et al. 2014, Cedeño-Laurent et al. 2018]. Tomorrow's workers who do not report to a central location may suffer disparate health outcomes because of missing these worksite features; alternatively, they may benefit if they can access programs (such as physical activity workouts) virtually from their mobile or home environment or if the latter is safer and healthier than a central location.

One major byproduct of changing organizational design that is intrinsically linked with job flexibility and that warrants concerted attention is work-life fit. In the coming years, workers will face an even greater need to concurrently manage work and personal life responsibilities, due in large part to globalization, innovative technologies (Goal 6), workforce demographic shifts (Goal 7) [Organisation for Economic Co-operation and Development 2011], and external issues impacting the workplace, work, and workforce (such as the COVID-19 pandemic). Flexible arrangements (working from home, accommodating start and stop work times, and taking time off when needed, for example) have become one of the most popular mechanisms for enhancing work-life fit, under the premise that flexibility aids workers' efforts to balance competing work and personal demands. A majority of related studies have highlighted the positive effects of flexibility, such as increased job performance, satisfaction, empowerment, autonomy, creativity, and opportunities for historically disadvantaged groups [O'Neill et al. 2009, Lange 2012, McNaughton et al. 2014]. However, others have shown that flexibility contributes to the blurring of boundaries between work and personal life domains, which can exacerbate work-family conflict and work-related stress [Bowen et al. 2017, Ray et al. 2021].

Importantly, flexibility opportunities (and related benefits) that provide work-life fit can differ on the basis of worker versus employer needs and voluntary versus imposed offerings. Furthermore, work-life boundary preferences impact the effectiveness of flexibility options and can account for why some options function well and some do not. The broader concept of control over work that extends beyond flexibility-into the where, when, and how work is done-may be even more significant than flexibility in its most narrow sense and therefore central to work-life fit issues [Kossek et al. 2018]. These and other considerations provide additional evidence that one size does not fit all and that offering employees as many safe 
and healthy options as possible to suit individual and evolving needs is key [Kossek et al. 2018]. Finally, the advantages associated with work-life fit and flexibility are additionally compounded by access to employer-sponsored leave (such as paid time off for vacation, illness, and caregiving), which stand to become even more complicated as non-standard work arrangements (Goal 3), multinational employers, and multiple job changes impact workers' access to these benefits [Asfaw et al. 2012, 2017].

Chronic stress is another increasingly critical worker issue that has been linked to myriad negative health outcomes, including burnout (unmanaged chronic stress), anxiety, depression, frustration, and physical complaints [Ganster et al. 2013]. Indeed, nearly two-thirds of adults identify work as a significant source of stress [Ray et al. 2017, American Psychological Association 2019]. Researchers expect this figure to grow as workers face increasingly blurred work-life boundaries, greater demands for work availability and flexibility, and decreased human connections because of remote work and the use of robots (Goal 5) in the workplace [Gabriel et al. 2016]. To that end, organizational-level factors (including other organizational design sub-priority topics in Figure 1) play a huge role in stress amelioration or exacerbation [Hammer and Brady 2021, Hammer et al. 2021]. They do so by contributing to more intermediate outcomes that, in turn, contribute to worker stress. These may include unhealthy leadership and low co-worker or supervisor social support (leading to work-life conflict); shift work and long work hours (causing fatigue); high workload (producing little or no job control); lack of resources (limiting ability to perform job tasks); inadequate pay and benefits (leading to economic insecurity (Goal 8)); low organizational justice (contributing to unfair treatment); and threats of workplace violence, harassment, or discrimination (posing risks to physical and psychological safety) [World Health Organization 2020].

Additionally, the interaction between these stress-related factors, external issues (emergency and disaster preparedness and response, politics, and social disruption, for example), and individual worker circumstances can intensify generalized stress, occupational stress, burnout, and associated outcomes (such as mental health issues) even more so [American Psychological Association 2020]. Ideally, managers and workers will develop comprehensive interventions together that maximize benefits by including both organizational changes (such as increased support and resources) and stress management practices [LaMontagne et al. 2007, Nielsen et al. 2010, Hammer et al. 2013, 2019]. Such interventions could additionally benefit by including other partners such as labor unions, which can serve an important role in safety and health programs and in advancing overall worker well-being [Center for Construction Research and Training 2018, Zoorob 2018, McNicholas et al. 2020, Soujourner et al. 2020].

Amid evolving organizational changes, leadership will certainly continue to play a key part in protecting and promoting worker safety, health, and well-being. New ways of working will provide opportunities for innovative, healthy leadership approaches (grounded in evidence-based supervisor support training) [Hammer and Brady 2021, 
Hammer et al. 2021] that create conditions which support and empower future workers by demonstrating respect, appreciation, and health awareness; distributing rewards fairly; communicating clearly; and advocating for job control and autonomous decision-making [Jiménez et al. 2017].

Correspondingly, research shows an increased need for organizations to prioritize societal interests over profits, known as Corporate Social Responsibility (CSR) [Bénabou et al. 2010, The President's Council of Advisors on Science and Technology 2020], and to engender mutual benefits across entities, known as Creating Shared Value (CSV) [Porter et al. 2011], both of which can be applied to leadership, business performance, and workplace well-being [Pronk et al. 2021]. Although some definitions and programs involving employee safety and health have been criticized as focusing more on social control than social responsibility [Holmqvist 2009, DeJoy et al. 2018], a growing body of research touts CSR and CSV as important psychosocial risk management strategies, which can provide workers with valuable resources and work-life benefits. These include continuing education, safe work environments and ethical labor practices, diversity and inclusion policies, community engagement opportunities, access to affordable and quality childcare and eldercare options, and other social protections, thereby enhancing the quality of working life [Jain et al. 2011, Rupp et al. 2015].

\section{Objectives}

- Use validated surveys to examine and enhance objective and subjective worker safety, health, and well-being outcomes and trajectories associated with changes to organizational design policies, programs, and practices due to external issues (for example, the "Great Resignation").

- Expand research on the antecedents and consequences of stress and burnout (such as mental health issues), especially in occupations with the highest rates.

- Define and evaluate differences in worker-governed flexibility versus employersanctioned flexibility to determine safety, health, and well-being effects; share associated examples and case studies; and provide relevant training and education.

- Assess worker well-being benefits and challenges associated with a range of workplaces (such as offices/dedicated facilities, homes, and vehicles) and modifications to built work environments.

- Identify and evaluate healthy leadership practices for workers in different locations (office versus home, for example).

- Conduct research on changes in the work/non-work interface and blurring of boundaries due to external issues (such as COVID-19 pandemic-related increases in telework; and remote, virtual, and hybrid work) and their impact on safety, health, and well-being outcomes for workers and their families. 
- Investigate the mental and physical health effects of working in a 24/7 "always open" economy.

- Explore and benchmark CSR and CSV among public health, business and industry, and communities to benefit the health and well-being of workers.

\section{Goal 2: Determine and address worker issues related to automation, technological job displacement, and occupational polarization}

\section{Background}

Technological advancements can result in job displacement, which occurs when jobs or associated tasks traditionally performed by workers are replaced by technology (Goal 6). Estimates of the magnitude and distribution of technological job displacement vary by occupation, industry, and worker socio-demographic characteristics (Goal 7). As such, the number of job losses is debatable and difficult to forecast. Whereas automation and computing may accomplish tasks such as data collection and processing more efficiently [Frey et al. 2017] and thereby encouraging technological job displacement, occupations in which workers have non-routine and interactive tasks are less likely to be completely mechanized [Arntz et al. 2016, Manyika et al. 2017]. Nevertheless, studies suggest that roughly half of U.S. employment could be fundamentally affected or altogether replaced by computers and algorithms [Frey et al. 2017]; within jobs, some studies project that about half of all tasks could be automated [Frey et al. 2017, McKinsey Global Institute 2017].

Though overall rates have been changing more rapidly, history shows that technological adoption is often slow, providing time for new task and job creation to compensate for job loss from automation [National Bureau of Economic Research 2018]. For instance, changes in work arrangements (Goal 3) may enable some displaced workers to acquire new skills (Goal 9) and become more competitive in the new labor market, further offsetting some technological job losses. Emerging technologies (Goal 6) have also traditionally created new jobs as a result of fundamental changes to work, the rise of new industries [Bessen 2015, Mokyr et al. 2015], and fluxes in consumer demand, contributing to overall job and economic growth and development, as well as increases in labor demand and productivity.

That said, technological advancements can have adverse impacts, too. In addition to eliminating jobs, they may lessen their quantity and quality; alter the availability of stable and new jobs; create temporary or unstable employment; make certain roles redundant (obsolete); and deeply change many occupations and even entire industries. In this process, occupational polarization can also occur, whereby 
technology (Goal 6) replaces middle-skill work often performed by some, more so than high- and low-skill work performed by others [Hirschi 2018, Vermeulen et al. 2018]. This disparateness is because many high-skill jobs (such as those held by managers, professionals, and technicians) require non-routine tasks with a higher order of thinking, problem-solving, or unique social interaction that cannot be automated at this time. Similarly, many low-skill workers who perform non-routine tasks (such as health and personal services, cleaning and protection services, and operation and labor) cannot easily be substituted with technology (Goal 6). However, middle-skill jobs include tasks that are predominantly routine-based (such as production, office and administration, and sales) and thus can more easily be automated; these are associated with a possible decline in employment, disproportionately affecting women, immigrants, and younger workers [Abraham et al. 2012]. The disappearance of middle-skill jobs may also make it harder to convert lower-wage service jobs into better ones, therefore limiting career opportunities [Dwyer et al. 2019]. Still, while middle-skill jobs are currently most at risk, some lower-skill jobs (such as in the food sector and transportation) may also be subject to increased displacement due to technology (Goal 6).

Technological job displacement also has vast implications for worker safety, health, and well-being. The perception of a future lacking in employment opportunities and economic security (Goal 8), and the need to acquire new job skills (Goal 9), may not only reduce the bargaining power of workers relative to management-making them more reluctant to raise concerns related to unsafe conditions-but may also lead to increased anxiety, depression, suicide, and alcohol and drug abuse (including opioid-related deaths) [McGee et al. 2015, Case et al. 2017, Hollingsworth et al. 2017]. Effective strategies to address these and other adverse effects have been proposed, such as upgrading unemployment insurance by making it easier for workers to receive partial benefits after the loss of a second job and not requiring individuals to seek full-time work to receive benefits [Autor et al. 2020].

Considerations and changes due to the COVID-19 pandemic may lead to automation becoming even more widespread by reshaping labor markets (including through remote work) and by occurring at an accelerated pace (despite historically occurring at a slower one) due to the introduction of new technologies (Goal 6) and work arrangements (Goal 3). Although these developments may create more efficiency in the long-term, in the short- and medium-terms, technological job displacement overall may adversely affect many workers, especially the least economically secure (Goal 8) [Autor et al. 2020].

\section{Objectives}

- Track the magnitude and distribution of technological job displacement of workers by industry, occupation, socio-demographic characteristics, and work arrangements.

- Assess how the rate and pace of change resultant from new technology implementation impact worker vulnerability and adaptability. 
- Increase research and translation activities on the impact of automation, technological job displacement, and occupational polarization on worker safety, health, and well-being, across occupations and industries.

- Evaluate safety and health outcomes for workers whose jobs or businesses are transitioned or lost because of external issues (such as the COVID-19 pandemic, extreme weather conditions, globalization, and social disruption).

- Assess the well-being implications of technological job displacement for workers (such as mental health) and for their families (such as children's health and future socio-economic prospects), employers, and society overall.

- Explore remedial and resiliency-building interventions that can better prepare or safeguard workers from potential job displacement or loss due to automation.

- Synthesize and periodically update forecasts of demand for new technologyrelated job tasks that might contribute to displacement in specific industries and occupations, to identify emerging safety and health issues.

- Develop and disseminate new OSH policies and practices for policy makers and employers aiming to prevent or mitigate the adverse consequences of occupational polarization.

\section{Goal 3: Identify and address the safety, health, and well-being risks for workers in different work arrangements}

\section{Background}

Long-standing, traditional surveys [Bureau of Labor Statistics 2001] are used to define, assess, and understand standard and non-standard (or alternative) work arrangements, the characterizations of which are different though not wholly mutually exclusive. NIOSH describes standard work arrangements as ones that are secure or permanent (career) [Bushnell et al. 2017, NIOSH 2019], whereby workers have employee status and more stable pay. They are also more likely to have access to health insurance, paid leave, and retirement benefits; have a regular, full-time work schedule; and the ability to negotiate their schedule and take time off. For non-standard work arrangements, which are typically classified in surveys as independent contractors, on-call workers, temporary help agency workers, and workers provided by contract firms [Bureau of Labor Statistics 2001], NIOSH considers a catalog of elements across two dimensions [Bushnell et al. 2017, NIOSH 2019]. Elements in the first dimension include:

- Job security (permanent, open-ended, limited)

- Work schedule (hours per week, shift [day, evening, night, rotating], predictability) 
- Compensation type (wage, salary, piece rate, job rate, profit, commission, training experience, intrinsic reward)

- Pay level and security (annual, weekly, or hourly earnings, variability of earnings)

- Benefits (such as health insurance, retirement benefits)

- Single versus dual or multiple employers (temporary help or staffing agency and client employer, subcontractor, and general contractor).

Elements in the second dimension include:

- Employee (permanent, temporary, intern)

- Self-employed (without business, with business)

- Volunteer.

Distinctions for concepts specifically related to non-standard work arrangements also include contingent work (a job that is not expected to last) and precarious employment [Bushnell et al. 2017, NIOSH 2019] (work with some degree of insecurity; temporariness; vulnerability to unfair treatment; inability to negotiate pay, benefits, and work schedule; lack of ability to take leave; and no social safety net, including unemployment and workers' compensation insurance) [Bhattacharya et al. 2021]. These differentiations are further used to understand certain aspects of newer types of non-standard work arrangements that have materialized over the years, such as "gig" ones, which are temporary, short-term commitments that arose in part due to the development and implementation of new technologies (Goal 6).

Though data from surveys assessing non-standard work arrangements do not reveal significantly increasing trends in their prevalence [Ray et al. 2017], the limitations in existing questions and the lack of universally accepted definitions across arrangement types do not allow in-depth assessments. Improper classification of worker status across arrangement types as employees or non-employees also occurs and is problematic, as it confuses who is legally responsible for protecting their safety and health [OSHA, NIOSH 2015]. For instance, some "gig" workers (at times erroneously classified as independent contractors rather than employees) hold other jobs [Katz et al. 2019], which may contribute to safety and health issues experienced at one job or the other (such as fatigue from long work hours). Multiple jobs held concurrently and other important aspects such as the sequence of jobs held over time, periods of unemployment, the availability of another job should the worker need or want to change jobs, and the context of all jobs held by a worker's family are also only marginally considered. These inadequacies restrict the ability to readily ascertain distinctions between work arrangements and their unique relationships to worker safety, health, and well-being outcomes [Benach et al. 2014].

To be sure, a study using data from 2002 to 2014 concluded that for some workers in non-standard work arrangements, such as independent contractors, increased job stress was associated with an increased number of self-reported unhealthy 
days [Ray et al. 2017]. This was similarly observed with activity limitations, as increased job stress was associated with increased reported days of activity limitations for workers in temporary help agency arrangements. What's more, work arrangements may be disproportionately impacted by other future of work topics, posing additional worker issues. Indeed, work arrangements are not only differently influenced by organizational design sub-topics (such as location where work takes place) (Goal 1) but also by technologies (Goal 6), demographics (such as when experiencing overlapping vulnerabilities) (Goal 7), workers' economic realities (Goal 8), and demand for newer skills (Goal 9). This demonstrates the need to study and address each arrangement type separately and in-depth, in addition to the combination of factors, to understand $\mathrm{OSH}$ implications more fully.

\section{Objectives}

- Develop and standardize definitions and taxonomy for work arrangements.

- Improve surveillance collection methods to include a wider selection of non-standard work arrangements that capture prevalence and trends of various types of work and more precise information about industry, occupation, and socio-demographics.

- Incorporate detailed data elements in surveillance systems of non-standard work to better assess, track, understand, and evaluate emerging safety and health hazards.

- Understand, estimate, and study the growth of prominent types of work arrangements due to other future of work-related changes (such as technologies, organizational design, and demographics).

- Study the overall effects of work arrangement types over the span of a working life, evaluating all jobs held simultaneously, the sequence of jobs, and periods of unemployment.

- Assess OSH training, compliance and protection policies, and injury and illness compensation and outcomes in relation to differences in responsibility for $\mathrm{OSH}$.

- Conduct intervention studies to assess the cost-effectiveness and comparative effectiveness of implementing safety and health programs for workers in nonstandard work arrangements.

- Develop best practice guidelines for addressing issues common among workers in non-standard arrangements (such as community-based participatory research to prevent workplace discrimination; identification of hazards without fear of retaliation; and implementation of education and training reflecting specific worker needs).

- Examine how broad external factors (such as extreme weather conditions, globalization, access to healthcare, and the economy) impact different types of work arrangements and their individual OSH outcomes. 


\section{Goal 4: Minimize worker risks and maximize benefits associated with artificial intelligence application}

\section{Background}

Artificial intelligence (Al) is achieved through computer algorithms and sensing technologies (Goal 6) that perform tasks involving complex data analysis and decision-making. More specifically, Al has the capability of analyzing large amounts of data in a fraction of the time it would take a human, allowing a wide variety of tasks to be automated. Machine learning (ML) is an application of Al permitting machines to improve their problem-solving abilities on their own, with experience. Applications of $\mathrm{Al}$ and $\mathrm{ML}$ touch almost every occupational sector [West et al. 2018] and are growing in the U.S., with the global AI market estimate expected to increase dramatically [Expresswire 2021], leading to favorable as well as potentially unfavorable outcomes.

Without a doubt, Al offers many benefits, including direct improvements to worker safety, health, and well-being, by removing humans from repetitive, dangerous, or hazardous tasks and locations. For example, autonomous systems can be used to perform monotonous or highly stressful data analysis and monitoring, thereby mitigating worker fatigue and associated mistakes with safety implications [Rogers et al. 2019]. Additionally, Al ethically combined with wearables can be used as a predictive medical device across industries to monitor heart rate variability (an indicator of cognitive fatigue), core body temperature, maximal oxygen consumption (a reflection of cardiorespiratory fitness), motion (including fall detection), and respiratory rate [Martin 2019]. Further advantages have largely been observed in improved surveillance and data analysis, reliability of risk assessment, OSH training methods, and automated medical screening and diagnosis [Tamers et al. 2020]. In the years that ensue, using supplementary methods to incorporate $\mathrm{Al}, \mathrm{ML}$, and neural networks (algorithms that imitate a human worker to identify relationships between copious amounts of data) into $\mathrm{OSH}$ research, surveillance, and mitigation also has potential, as will developing and implementing programs that analyze and model occupational health data to predict safety and health outcomes.

The total impact of increased Al adoption on the OSH field and worker safety, health, and well-being remains unclear. For instance, Al is employed in the use of robotics and driverless vehicles (Goal 5), raising concerns about its decision-making ability as it relates to safety, especially when humans are in proximity. Al may also contribute to prospective job displacement (Goal 2) and retraining needs (Goal 9) [International Labour Organization 2019], leading to an increase in psychological and other worker health risks. Ultimately, proactive steps are needed to test and evaluate Al systems and algorithms and use appropriate risk-benefit analysis. Doing so with the participation of key parties such as labor unions will help limit worker OSH-related exposures and hazards (such as outside interference and cybersecurity threats), discrimination, bias, and inequity [Vietas 2021]. 


\section{Objectives}

- Conduct collaborative studies with employers to ascertain unintended consequences of Al applications (such as job insecurity or loss) on worker safety, health, and wellbeing.

- Study potential issues of vigilance and under- or over-trust for workers who use systems that employ Al.

- Explore mechanisms to ethically incorporate Al into occupational research, surveillance, and mitigation, with a focus on the development and utilization of programs that can model and analyze occupational health data.

- Advance the use of ML to develop automated approaches for evaluation and classification (for example, of medical images used in surveillance for pneumoconiosis and other occupational lung diseases).

- Research the development, use, and acceptance of Al for OSH risk assessment and control.

- Investigate the use and acceptance of augmented human decision-making in safety risk reduction in the workplace.

- Investigate and reduce the risks associated with the use of Al and computer vision to detect and prevent incidents involving contact between a human worker and a collaborative robot, autonomous mobile robot, or unmanned vehicle.

- Reduce worker cognitive and psychological burden through Al systems that identify, prioritize, and effectively communicate to workers the most relevant information they need to conduct tasks.

- Assess Al cybersecurity vulnerabilities and relationships with worker productivity and job displacement.

- Test and evaluate Al systems and algorithms to reduce worker discrimination and bias, address health equity and ethics concerns, and improve socio-demographic representativeness.

\section{Goal 5: Mitigate worker safety and health challenges and leverage opportunities associated with robotics}

\section{Background}

Robots carry out physical actions and make informed decisions. For years, the traditional industrial robot typically used in certain settings like manufacturing performed limited tasks and was physically separated from human workers [International Federation of Robotics 2019]. Since then, new types have been 
developed and their popularity is rapidly growing. These robots not only make calculated choices but can also sense their environment, perform independently, work with or in the same space as human workers (collaborative robots, or "co-bots"), and even be worn by them (powered and non-powered exoskeletons and exosuits).

Robots offer potential for improving and making safer work that is customarily performed by humans, by producing opportunities to streamline processes and limiting hazardous exposures particularly evident in some occupations and industries [Tamers et al. 2020]. Such is the case with robotic systems, which modify the environment in extreme weather conditions by doing work or misting workers to help offset hazards in construction, and by mixing and processing chemicals to reduce dermal and respiratory exposures in foundries. In addition, robots in both traditional healthcare settings (such as hospitals) and non-traditional ones (such as in the home, providing service to the homebound) can serve as worker adjuncts. For their part, unmanned aerial vehicles (UAVs, or drones) are employed more and more to assess worksites and structures and are piloted for delivery of goods (such as medical supplies during the COVID-19 pandemic [Kretchmer 2020]). Fully automated vehicles are also used for delivery of commercial goods, piloted for transit of people, and used to cart materials in mining [Howard et al. 2018].

Benefits aside, workers may be physically or psychologically harmed from hazardous contact as more businesses bring in collaborative and mobile robots [Murashov et al. 2016, Howard et al. 2018, 2020], and new and still unknown safety risks may present themselves due to advances in fully and partially automated vehicle technologies [American Society of Safety Professionals 2019a]. For instance, workers may face increased risk by losing situational awareness and inadequately reacting to hazards while in the company of robots, which has been documented in fatal crashes with highly automated vehicles [National Transportation Safety Board 2020]. Given that robots ultimately impose the pace of work, workers may also experience amplified stress associated with changes in how and the speed at which work is performed.

Robots are now increasingly employed across industry sectors and in community and outdoor settings; as a result, some guidelines and requirements that promote safe interaction have been introduced [International Organization for Standardization 2012]. Moving forward, expanding applications of robots and human-machine interaction will require careful balancing and consideration, as well as evidence-based recommendations to ensure the safety and health of workers.

\section{Objectives}

- Evaluate the benefits and risks of robotics, to include human-machine interaction, human action recognition, and intent prediction of robots in highly impacted jobs, occupations, and industries (such as transportation, manufacturing, foundries, mining, and welding). 
- Investigate potential consequences of drones, autonomous vehicles, other remotely controlled mobile equipment, exoskeletons, and exosuits on worker safety, health, and well-being.

- Examine the human-machine interface to determine what and how much is needed, challenges when suboptimized, and the psychosocial impact on those working with new robotics technologies (including stress in using technologies not fully understood and concerns about subservience to the technology).

- Determine how to effectively disseminate knowledge about the development and evaluation of exoskeleton systems and ergonomic-related issues in the use of robots.

- Assess and improve design standards for robots to address safety concerns and increase worker trust.

- Explore and evaluate robotics technology and relevant education and training to improve worker safety and health equity for disadvantaged groups.

- Conduct research to understand the impact of the emerging commercial use of unmanned aerial vehicles in relation to potential deaths and injuries from falls, toxic chemical exposures, electrical hazards, and collisions (such as in transportation, construction, agriculture, utilities, public safety, and mining).

- Perform comparative-effectiveness and cost-effectiveness studies examining whether advantages of robotic safety replacements outweigh the toll of displacement for workers who cannot be retrained or re-assigned.

- Design interventions that improve safe adoption of advanced driver-assistance system features, including ensuring workers remain engaged while driving vehicles that are partially automated, to inform best management practices.

\section{Goal 6: Evaluate the impact of innovative and emerging technologies on worker well-being}

\section{Background}

New and developing technologies that characterize Industry 4.0 and that are still very much at the forefront of the next industrial revolution in motion, Industry 5.0 [European Commission 2021], have profoundly reshaped and reorganized the workplace, work, and workforce in both advantageous and disadvantageous ways yet to be fully determined.

To begin, developments in nanotechnology, smart materials, and other technologies offer new capabilities for manufacturers and engineers. Additive manufacturing (or 3D printing) has improved design optimization, facilitated collaboration, promoted 
quicker design iteration, and limited the need for as many assembly lines; this process now makes it simpler to fulfill demand and enable just-in-time production [Berman 2012, Campbell et al. 2013]. For its part, advanced computing, which employs vast amounts of data from ever-increasing numbers of sensors available at ever-decreasing costs, improves decision-making and asserts action in almost every industry [Bloem et al. 2014, Falkenthal et al. 2016].

Sensors and controls that connect to the Internet-of-Things [Falkenthal et al. 2016] can collect, integrate, and analyze data from a distributed industrial network to not only improve assessment of different workplace safety and health hazards [Chui et al. 2010] and productivity, but also remotely monitor and control large numbers of devices at different locations. Doing so has transformed many jobs and processes to a single set of computer tasks, enhancing efficiency [Bloem et al. 2014, Falkenthal et al. 2016]. Moreover, information and communication technologies enable data collection, aggregation, processing, and decision-making to occur in disparate locations, a capability which is increasingly vital as more organizations become global, with inter-reliant operations among facilities in various locations. Beneficial changes have also occurred through breakthroughs in computing, economical equipment, and new techniques such as synthetic biology, leading to biology-based processes that replace traditional manufacturing [Friedman et al. 2015, National Academies of Sciences 2015].

Such abilities and flexibilities have improved both productivity and safety by notifying workers of hazards, sustaining processes within risk tolerance parameters, and aiding risk management decisions [Bloem et al. 2014]. Still, these advancements have not been devoid of new hazards with worker wellbeing challenges. Workers who are closely monitored may take risks to maintain productivity or find ways to foil specific data collection [Tomczak et al. 2020], while those who manage different devices at once (especially during a crisis or emergency) might experience cognitive overload and resulting psychosocial issues [Schulte et al. 2020]. Emerging technologies can also expose organizations and their workers to unintended risks such as hacking, algorithm manipulation, and confidentiality and privacy issues related to $\mathrm{Al}$ (Goal 4) and cybersecurity [West et al. 2018]. Indeed, technologies (Goal 6) used to collect worker-level information (such as early indicators of chronic disease) can be misused and promote discriminatory employment practices. Despite offering greater functionality than traditional sensors [Falkenthal et al. 2016], advanced or "smart" sensors, which can be surgically placed in the body, worn or embedded in safety clothing, or attached to a workplace object [Nag et al. 2017, Metz 2018] may elicit privacy concerns associated with the monitoring and tracking of all aspects of worker performance.

Given the anticipated transformations to the world of work, current and evolving technologies may need to be rethought as they are expanded to a new scale of workers with different workplace and work preferences and expectations; skill sets and training needs (Goal 9); and OSH considerations. 


\section{Objectives}

- Compile, improve, and disseminate data sources that inform policies, programs, and practices evaluating the impact of new technologies on exposures and hazards.

- Track positive and negative consequences and changes on worker safety, health, and well-being from using sensors, manufacturing processes, and the Internet-of-Things rather than traditional technologies.

- Examine the impact of advanced materials and additive manufacturing on worker outcomes (such as respiratory and dermal exposures) in various workplace settings (such as schools, manufacturing, and startups).

- Consider how technologies affect the supervision of work, the overall quality of work life, and productivity.

- Assess the impact of biology-based processes on a greener economy and worker health.

- Evaluate the cost-effectiveness of workers using engineering controls and smart PPE to reduce exposures for those who develop and use technologies.

- Assess the joint effects of technologies and other changes to the workplace and work (such as extreme weather conditions, infectious disease outbreaks, sociodemographic shifts, and non-standard work arrangements) on worker well-being.

- Create best practices to ensure ethical monitoring and surveillance (including informed consent), protect privacy, and prevent discrimination and penalization for workers whose data are collected by sensors.

- Design risk assessment guidance, control methods, and protocols to inform, train, safeguard, and empower workers to develop and use technologies safely and ethically.

- Anticipate and minimize potential adverse worker effects (such as lack of autonomy and job control) on worker well-being, early in the development and implementation of new technologies.

\section{Goal 7: Identify, examine, and reduce the inequitable distribution of work-related risks and benefits due to demographic characteristics}

\section{Background}

The U.S. population has been undergoing dramatic demographic shifts, a trend that will continue in the coming decades. This has contributed to growing worker 
diversity and a more widespread effort to recruit and foster an inclusive and representative workforce along dimensions such as age, class, gender identity and sexual orientation, nativity, race/ethnicity, disability, and immigrant status.

The future of work is steeped in technological developments (Goal 6) that have significantly contributed to worker well-being and reductions in workplace injuries and illnesses [Dogan et al. 2019, Toxiri et al. 2019, Calzavara et al. 2020], and which can be observed across different demographic groups. For instance, technologies (Goal 6) that enable remote work have supported workers with disabilities who are more likely to work from home compared to workers without disabilities [Schur et al. 2020], while the rise in non-standard work arrangements (Goal 3), such as "gig," contract, freelance, and other types of independent work that offer greater flexibility have attracted more women workers [Palagashvili et al. 2021].

However, workers who have been traditionally underserved, such as women, racial/ ethnic minorities, older adults, immigrants, and those living with a disability still do not benefit equally from these advances. One reason is that scientific assumptions behind the development of technologies (Goal 6) still in use today (such as the assumption of a 70-kg [154-lb] man in toxicology or the use of mid-20th century anthropometric data from military recruits to create PPE) were often biased toward more conventionally accepted worker groups such as white men [Hsiao 2015]. Consequently, for other groups, the protective efficacy of these new technologies (Goal 6) has been sub-standard [Zou et al. 2018, Perez 2019]. This is despite the fact that the percentage of workers identifying as part of one or more currently disadvantaged groups is growing [Kitt et al. 2013]. As a result, there is a push to develop more comprehensive and flexible design practices to help refine existing technologies (Goal 6) or create new ones in an effort to ensure OSH standards are appropriate for the entire workforce.

Fostering inclusive research practices to produce data-driven solutions that reduce inequities is also an indispensable step toward safeguarding the well-being of an increasingly diverse workforce. The field of OSH has evolved into a largely technical one that is generally guided by a reductionist view of cause and effect, focused on isolating and eliminating proximate factors that result in workplace hazards [Flynn 2018]. Research on the technical aspects of OSH has been historically favored over research that explores the social context and relationships that circumscribe occupational health outcomes [Peckham et al. 2017, Schulte et al. 2019].

Accordingly, some segments of the workforce continue to be underrepresented in OSH research (for instance, underserved worker populations such as immigrants and those in low-wage or highly constrained jobs) [Kossek et al. 2018] and therefore benefit less from interventions and emerging technologies (Goal 6) designed to protect workers [0'Connor et al. 2011]. Indeed, this longstanding imbalance has led to research questions, funding decisions, data collection instruments, and scientific assumptions that are-perhaps inadvertently-not indicative of a diverse population [Hsiao 2015, American Society of Safety Professionals 2019b, Flynn et al. 2021]. 
Moving forward, effectively documenting the OSH status of a diverse workforce will require more sweeping research and data collection methods from a greater range of disciplines [Souza et al. 2010, Flynn et al. 2014]. It will also require consideration of varied life perspectives by hiring more researchers from diverse backgrounds, using grass-roots methods such as community-based participatory approaches [Eggerth et al. 2010], and including analytical strategies that account for the intersectional aspect of social identity and overlapping structural vulnerabilities [NIOSH and American Society of Safety Professionals 2015, Ceballos et al. 2020].

The COVID-19 pandemic has spotlighted the asymmetrical power relationships that persist across demographic characteristics and that result in social, economic, and environmental hindrances impacting the distribution of work-related benefits and risks [Tamers et al. 2020]. Undeniably, changes to organizational design (Goal 1), technological job displacement (Goal 2), and work arrangements (Goal 3) have brought $\mathrm{OSH}$ advantages and disadvantages, which are dispersed differently [Quinlan et al. 2004]. As time progresses, the OSH field and society at large will need to better understand these disparities and more equitably allocate the benefits of workplace and work changes-while mitigating risks - to truly discern how diversity impacts $\mathrm{OSH}$, ensure the well-being of all workers across the U.S. [Pronk et al. 2021], and advance in the global economy collectively and fairly.

\section{Objectives}

- Pinpoint gaps and opportunities in the inclusion of key demographic variables in worker safety, health, and well-being surveillance systems and research projects.

- Explore how age, class, gender, nativity, race/ethnicity, disability, and immigrant status overlap with one another and influence the distribution of OSH risks and benefits associated with evolving organizational design, technological job displacement, work arrangements, and geographic dispersion (urban versus rural community settings, across the U.S., and cross-country comparisons).

- Develop methods to minimize bias in the scientific assumptions and programming that underlie technology-based designs for PPE and other protective equipment such as exoskeletons (for example, use research and computer modeling to include more diverse anthropometric data).

- Design interventions that ensure fair distribution, across demographic groups, of the advantages and mitigation of the risks associated with changes to the workplace and work.

- Apply analytical strategies and data collection methods designed for diverse workers to identify how improving access to the protective aspects of evolving organizational design and work arrangements could reduce worker health disparities.

- Examine how different demographic variables contribute to the distribution of economic security among workers across the U.S. and their access to skills needed to advance in the global economy. 
- Produce and test culturally tailored interventions that address barriers to safety, health, and well-being.

\section{Goal 8: Reduce adverse worker safety, health, and well-being effects resulting from economic insecurity}

\section{Background}

Economic security is broadly defined as having adequate income and assets; access to benefits; some control over job content and an opportunity to build a career; individual and collective rights; the opportunity for income-earning activities; protection of income-earning work; working conditions that are safe and healthy; and the chance to gain and retain skills (Goal 9) [International Labour Organization 2015]. Economic security is also a critical determinant of worker well-being [Daly et al. 1998, Theodossiou 1998, Asfaw et al. 2011, 2017, Leigh et al. 2012, Ray et al. 2012, Du et al. 2015, Lowrey 2018], but it is not guaranteed or distributed equally across workers.

Fortunately, many effective strategies for improvement already exist or are developing, including providing more schedule and location flexibility; generating portable benefits systems for workers with no traditional employers; creating and expanding supports for technologically displaced workers; and re-aligning employer incentives for investing in workers. Although these and other changes in the complex relationship between the technologies (Goal 6) and labor needed to produce goods and services have positive implications for workers' economic security, some negative consequences persist [McKinsey Global Institute 2017].

To be sure, advances in technologies (Goal 6) have increased productivity, resulting in higher overall incomes [National Bureau of Economic Research 2018]. However, the shifting relationship between workers and employers and the pressure on organizations to focus on immediate results rather than long-term value have created new challenges [Aspen Institute 2019]. One such example is automation leading to technological job displacement (Goal 2) and increased inequity across demographic groups (Goal 7) [Acemoglu et al. 2018], with adverse worker safety, health, and wellbeing outcomes, including job and economic insecurity [Manyika et al. 2017].

Various aspects of organizational design (Goal 1), such as flexibility in schedule, location, and work arrangements (Goal 3), can also undesirably affect workers' economic security. Compared to workers in permanent, full-time jobs, workers in nonstandard work arrangements (Goal 3) frequently earn less income, have fewer benefits, work in less safe and healthy environments, and experience more precariousness [Bhattacharya et al. 2021]. In addition, businesses continue to face shareholder pressure to produce short-term profits, foregoing investments in their workforce that 
would create value in the long term [Aspen Institute 2019]. These pressures occur despite recommendations put forth that would provide employers with incentives to increase their investment in employee training (Goal 9), including how accounting standards treat training costs [International Labour Organization 2019].

Indeed, financial accounting standards classify costs associated with workers as expenses even though equipment and other tangible goods are considered as assets; as a result, employers optimize the latter and minimize the former [Coff et al. 1993]. Ongoing changes in socio-economic and demographic worker characteristics (Goal 7) also have financial consequences. For instance, a larger proportion of older individuals are staying in or returning to the workforce in part because of insufficient means to support their retirement, and women who are increasingly represented in the workforce still face stark pay inequities compared to men [Toosi 2013].

Though millions of workers are currently leaving their jobs in search of other opportunities with increased flexibility and better wages and benefits [National Public Radio 2021], the COVID-19 pandemic has also exacerbated aspects of economic security disproportionally affecting certain categories of workers. Undeniably, many workers and their families were (and continue to be) severely impacted through the temporary or permanent loss of jobs and the related loss of income and access to benefits. This widespread economic security effect will likely have personal health and OSH implications for years to come, particularly for the unemployed and underemployed, and will require the collective attention and assistance of all interested parties.

\section{Objectives}

- Gauge the impact on worker well-being of economic insecurity dimensions (such as inadequate wages, inequitable and incommensurate compensation and benefits, and lack of minimum guaranteed hours).

- Track the overall level and distribution of both perceived and objective indicators of economic security and their impact on worker safety, health, and well-being and on workers' families, employers, and society by industry, occupation, work arrangement, and demographic worker characteristics.

- Evaluate the short- and long-term consequences of economic and health shocks (such as the COVID-19 pandemic) on economic security indicators (such as women's employment trajectories and opportunities) and other related safety, health, and wellbeing dimensions (such as worker empowerment).

- Measure improvements in worker well-being due to employer- and government-level prevention and mitigation strategies addressing economic insecurity. 


\section{Goal 9: Assess continued education, training, and skill-building needs and approaches to improve OSH outcomes}

\section{Background}

By 2025, 85 million current job roles could be made redundant, while 97 million new roles may be created or adapted [World Economic Forum 2020]. These employment changes will have implications for education, training, and skills, along with effects on worker safety, health, and well-being. In particular, industries with workers who will likely have the greatest need for skill-building due to a higher risk of technological job displacement (Goal 2) include accommodations and food service, wholesale and retail trade, transportation, education, construction, manufacturing, and health care and social assistance [World Economic Forum 2016]. Within these industries, women, younger workers, and those with lower socio-economic status or in temporary employment may be impacted even further [Organisation for Economic Co-operation and Development 2016, Bureau of Labor Statistics 2020].

Many employers have already shown interest in supporting and investing in workforce development, with 30\% temporarily re-assigning workers to different tasks; $35 \%$ accelerating the implementation of up-skilling and re-skilling programs; and $42 \%$ increasing the use of online, digital, or new methods of education and training [World Economic Forum 2016]. Still, such measures will survive only if employers perceive economic and other benefits by way of a return on investment (ROI) or value on investment (VOI) and if they are equipped for workforce development [Newman et al. 2020]. Employers and businesses are largely open to some form of continued education, re-training, re-skilling, or up-skilling as they adapt to incorporate new technologies (Goal 6) and organizational design processes (Goal 1) to increase production and competitiveness. At the same time, they are re-evaluating their workforces even more so to determine which skills are indispensable and which current and future workers are needed [Manyika et al. 2017].

To aid this process, efforts have ensued to address skill shortages, gaps, and mismatches [Cappelli 2015], and varied nomenclature and classification models have been proposed for the hard, soft, and cross-functional (transferable) skills necessary for career sustainability [Skills Framework for the Information Age 2000, Hamilton 2012, Handel 2016, Skills Future 2016, European Commission 2017, Siekmann et al. 2017]. Though viewpoints differ on precisely which skills are required, most evidence points to an array of skills that many workers will need to have in all job categories as the future unfolds [Institute for the Future 2020]:

- Sense-making (assessing the underlying meaning or significance of what is being articulated) 
- Social intelligence (connecting with others in a profound and direct manner)

- Novel and adaptive thinking (thinking and creating solutions and responses beyond the status quo)

- Cross-cultural competency (operating in diverse cultural settings)

- Computational thinking (translating data into abstract ideas and comprehending data-based reasoning)

- New-media literacy (determining, developing, and communicating content that uses new media forms)

- Transdisciplinarity (being literate in translating concepts across multiple disciplines)

- Design capability (representing and developing tasks and work processes for intended outcomes)

- Cognitive load management (differentiating and sieving information for importance and maximizing cognitive functioning with various tools and techniques)

- Virtual collaboration (working productively and engagingly in a group virtual setting).

Workers will need to acquire these aptitudes and possess other relevant human capital elements (skills, knowledge, and experience embodied by a worker and assessed with respect to their value or cost to an organization) [Capitals Coalition 2021] to transition more quickly and meet volatile labor markets, automation, and employer demands [Akerman et al. 2017, Flores et al. 2020]. Furthermore, given the negative outcomes associated with unemployment and underemployment [Friedland et al. 2003, McKee-Ryan et al. 2005, Paul et al. 2009], gaining a composite of such skills is not only fundamental to continued work but also equally fundamental to physical and mental well-being.

In addition to the worker-level skills needed, organizational-level frameworks and initiatives to prepare the emerging workforce are imperative. Regrettably, as has been previously published [Okun et al. 2016], most current frameworks do not include knowledge, skills, and abilities for safe and healthy work [Guerin et al. 2020]. Therefore, a unified approach involving a fusion of academic education, technical training, and hands-on experience [Heinrich 2015, McCarthy 2015]-ingrained with safety and health competencies [Occupational Hygiene Training Association 2021]is pivotal for meeting the needs and ensuring the overall well-being of the future workforce. Such an approach should also consider learning methods more readily acceptable to workers (such as not requiring a return to school for a supplementary and costly degree) [Felknor et al. 2021]; skills for leadership reflecting the changing dynamics in business and workplace management; training for OSH and allied professionals and practitioners who have a hand in any aspect of workforce development [Newman et al. 2020]; and active participation by communities who can help with certain OSH-related challenges both on- and off-the-job. 


\section{Objectives}

- Evaluate the psychological health and well-being of workers who are being re-trained or are resistant to training.

- Measure organizations' evolving human capital investment to determine worker wellbeing and productivity outcomes.

- Identify healthy leadership and management skill-building and training gaps to meet the changing needs of workers.

- Quantify industry leaders' operational risk management concerns about deficient worker OSH training.

- Assess facilitators and barriers to including foundational competencies that ensure job-specific safety skills as part of work readiness skill-building.

- Develop new, practical, and outcomes-focused learning and retraining methods for workers displaced by new technologies to prepare for future opportunities and help offset any psychological or other harms experienced due to job loss.

- Create tailored and integrated skill-related tools and resources based on job type, occupation, and industry to find impactful, long-term solutions, especially for workers at increased risk of safety and health hazards (such as younger or older workers, workers with disabilities, and non-standard workers).

- Incorporate best-practice guidance on essential skills for safe and healthy future work into the curricula of existing and new education, training, and skillbuilding programs, in consultation with employers, $\mathrm{OSH}$ and allied educators and professionals, academic institutions, professional and trade associations, labor unions, and state and local health departments. 


\section{REFERENCES}

Abraham L, Zenu S [2012]. Environmental corporate social responsibility and financial performance: disentangling direct and indirect effects. Ecological Economics 78:100-111.

Acemoglu D, Restrepo P [2018]. The race between man and machine: implications of technology for growth, factor shares, and employment. Am Econ Rev 108(6):1488-1542.

Akerman A, Ingvil F, Benedikt C, Osborne M [2017]. The future of employment: how susceptible are jobs to computerisation? Technological Forecasting and Social Change 114(c):254-280.

APA [2019]. Stress in America 2019. American Psychological Association, https:// www.apa.org/news/press/releases/stress/2019/stress-america-2019.pdf.

APA [2020]. Stress in America 2020. Stress in the time of COVID-19. American Psychological Association, https://www.apa.org/news/press/releases/stress/2020/ stress-in-america-covid.pdf.

ASSP [2019a]. ASSP TR-Z15.3-2019 Technical report: management practices for the safe operation of partially and fully automated motor vehicles. American Society of Safety Professionals, https://www.assp.org/standards/standards-topics/fleetmotor-vehicles-z15-1.

ASSP [2019b]. Women and safety in the modern workplace: creating a diverse and inclusive workplace can boost safety, productivity, profitability. American Society of Safety Professionals, https://www.assp.org/docs/default-source/default-documentlibrary/assp_women_and_safety_report_0419.pdf?sfvrsn=28.

Arntz M, Gregory T, Zierahn U [2016]. The risk of automation for jobs in OECD countries. OECD Social, Employment and Migration Working Papers, No. 189. Paris: OECD Publishing, https://doi.org/10.1787/5jlz9h56dvq7-en.

Asfaw A, Colopy M [2017]. Association between parental access to paid sick leave and children's access to and use of healthcare services. Am J Ind Med 60(3):276284.

Asfaw A, Pana-Cryan R, Rosa R [2011]. The business cycle and the incidence of workplace injuries: evidence from the U.S.A. J Safety Res 42(1):1-8.

Asfaw A, Pana-Cryan R, Rosa R [2012]. Paid sick leave and nonfatal occupational injuries. Am J Public Health 102(9):e59-64.

Asfaw A, Rosa R, Pana-Cryan R [2017]. Potential economic benefits of paid sick leave in reducing absenteeism related to the spread of influenza-like illness. $J$ Occup Environ Med 59(9):822-829. 
Aspen Institute [2019]. Solutions for a changing economy: a report from the Aspen Institute Future of Work Initiative National Advisory Council, https://www. aspeninstitute.org/wp-content/uploads/2019/10/Aspen-Institute-Future-ofWork-Initiative-National-Advisory-Council_Solutions-for-a-Changing-Economy_ October-2019.pdf.

Autor D, Mindell D, Reynolds E [2020]. The work of the future: building better jobs in an age of intelligent machines. MIT Task Force on the Work of the Future Reports, https://workofthefuture.mit.edu/research-post/the-work-of-the-future-buildingbetter-jobs-in-an-age-of-intelligent-machines/.

Autor D, Reynolds E [2020]. The nature of work after the COVID crisis: too few low-wage jobs. Brookings' The Hamilton Project, https://www.brookings.edu/wpcontent/uploads/2020/08/AutorReynolds_LO_FINAL.pdf.

Bartik A, Cullen Z, Glaeser E, Luca M, Stanton C [2020]. What jobs are being done at home during the COVID-19 crisis? Evidence from firm-level surveys. National Bureau of Economic Research Working Paper 27422, https://www.nber.org/system/files/ working_papers/w27422/w27422.pdf.

Bénabou R, Tirole J [2010]. Individual and corporate social responsibility. Economica 77(305):1-19.

Benach J, Vives A, Amable M, Vanroelen C, Tarafa G, Muntaner C [2014]. Precarious employment: understanding an emerging social determinant of health. Ann Rev Public Health 35:229-253.

Berman B [2012]. 3-D printing: the new industrial revolution. Bus Horiz 55:155-162.

Bessen J [2015]. Toil and technology. Finance Development 52(1):16-19.

Bhattacharya A, Ray T [2021]. Precarious work, job stress, and health-related quality of life. Am J Ind Med 64(4):310-319.

Bloem J, Doorn M, Duivestein S, Excoffier D, MaasI R, Ommeren E [2014]. The fourth industrial revolution. Things to tighten the link between IT and OT. VINT Report 3, https://labs.sogeti.com/research1/fourth-industrial-revolution-internet-thingstighten-link-ot/.

Bowen P, Govender R, Edwards P, Cattell K [2017]. Work-related contact, work-family conflict, psychological distress and sleep problems experienced by construction professionals: an integrated explanatory model. Construction Management and Economics 36(4):1-22.

Brenan M [2020]. COVID-19 and remote work: an update. Gallup, https://news. gallup.com/poll/321800/covid-remote-work-update.aspx.

BLS [2001]. Contingent work in the late-1990s. Bureau of Labor Statistics, https:// www.bls.gov/opub/mlr/2001/article/contingent-work-in-the-late-1990s.htm. 
BLS [2020]. Worker displacement: 2017-19. Bureau of Labor Statistics, https://www. bls.gov/news.release/pdf/disp.pdf.

Bushnell T, Scharf T, Alterman T, Cummings K, Luckhaupt S, Ray T, Rosa R, Su C [2017]. Developing a taxonomy of work arrangements to examine relationships with worker safety, health, and well-being. Presented at the 12th International Conference on Occupational Stress and Health. Minneapolis, MN: Work, Stress, \& Health 2017.

Calzavara M, Battini D, Bogataj D, Sgarbossa F, Zennaro I [2020]. Ageing workforce management in manufacturing systems: state of the art and future research agenda. Int J Prod Res 58(3):729-747.

Campbell T, Ivanova O [2013]. Additive manufacturing as a disruptive technology: implications of three-dimensional printing. Technol Innov 15:67-79.

Capitals Coalition [2021]. Social \& human capital protocol. Capitals Coalition, https://capitalscoalition.org/capitals-approach/social-human-capital-protocol/.

Cappelli P [2015]. Skill gaps, skill shortages, and skill mismatches: evidence and arguments for the United States. Industrial and Labor Relations Review 68(2):251-290.

Case A, Deaton A [2017]. Mortality and morbidity in the 21st century. Brookings Pap Econ Act Spring:397-476.

Ceballos D, Côté D, Bakhiyi B, Flynn M, Zayed J, Gravel S, Labrèche F [2020]. Overlapping vulnerabilities in workers of the electronics recycling industry formal sector: a commentary. Am J Ind Med 63(11):955-962.

Cedeño-Laurent J, Williams A, MacNaughton P, Cao X, Eitland E, Spengler J, Allen $J$ [2018]. Building evidence for health: green buildings, current science, and future challenges. Ann Rev Public Health 39:291-308.

CPWR [Center for Construction Research and Training] [2018]. Quarterly data report: union effect on safety management and safety culture in the construction industry. CPWR, https://www.cpwr.com/wp-content/uploads/2018/05/Quarter1-QDR-2018.pdf.

Chia G, Lim S, Sng G, Hwang Y, Chia K [2019]. Need for a new workplace safety and health (WSH) strategy for the fourth industrial revolution. Am J Ind Med 62:275-281.

Chui M, Loeffler M, Roberts R [2010]. The internet of things. McKinsey Quarterly, https://www.mckinsey.com/industries/high-tech/our-insights/the-internet-of-things.

Coff R, Flamholtz E [1993]. Corporate investment in human capital: how financial accounting standards undermine public policy. Stanford Law and Policy Review Fall:33-40.

Daly M, Duncan G, Kaplan G, Lynch J [1998]. Macro-to-micro links in the relation between income inequality and mortality. Milbank Q 76(3):303-339. 
DeJoy D, Dyal A-M, Smith T [2018]. Workplace health promotion: ethical tight rope. In: R. Burke \& C. Cooper, eds. Violence and abuse in and around organisations. London: Taylor-Francis, pp. 353-374.

Dogan O, Akcamete A [2019]. Detecting falls-from-height with wearable sensors and reducing consequences of occupational fall accidents leveraging IoT. In: Mutis I, Hartmann T, eds. Advances in informatics and computing in civil and construction engineering. Cham, Switzerland: Springer.

Du J, Leigh J [2015]. Effects of wages on smoking decisions of current and past smokers. Ann Epidemiol 25(8):575-582; e571.

Dwyer R, Wright E [2019]. Low-wage job growth, polarization, and the limits and opportunities of the service economy. RSF: The Russell Sage Foundation Journal of the Social Sciences 5(4):56-76.

Eggerth D, Flynn M [2010]. When the third world comes to the first: ethical considerations when working with Hispanic immigrants. Ethics \& Behavior 20(34):229-242.

Ellison J [2012]. Ergonomics for telecommuters and other remote workers. Interface 2:8-11.

Eurofound [2018]. Automation, digitization, and platforms: implications for work and employment. Luxembourg: Publications Office of the European Union, https:// www.eurofound.europa.eu/sites/default/files/ef_publication/field_ef_document/ ef18002en.pdf.

European Commission [2017]. ESCO strategic framework. European skills, competences, qualifications and occupations. ESCO, May, https://ec.europa.eu/ esco/portal/document/en/89a2ca9a-bc79-4b95-a33b-cf36ae1ac6db.

European Commission [2021]. Industry 5.0. Luxembourg: Publications Office of the European Union, https://op.europa.eu/en/publication-detail/-/publication/468a892a5097-11eb-b59f-01aa75ed71a1/.

Expresswire [2021]. Enterprise artificial intelligence market size-trends evaluation 2021 by consumer-demand, recent developments, leading players updates, strategies, and forecast till 2026 | industry research biz. Market Watch, https://www. marketwatch.com/press-release/enterprise-artificial-intelligence-market-size--trends-evaluation-2021-by-consumer-demand-recent-developments-leading-playersupdates-strategies-and-forecast-till-2026-industry-research-biz-2021-12-08.

Falkenthal M, Breitenbücher U, Christ M, Endres C, Kempa-Liehr A, Leymann F, Zimmermann M [2016]. Towards function and data shipping in manufacturing environments: how cloud technologies leverage the 4th industrial revolution. Research Gate, https://www.researchgate.net/publication/309476649_Towards_ Function_and_Data_Shipping_in_Manufacturing_Environments_How_Cloud_ Technologies_leverage_the_4th_Industrial_Revolution 16-25. 
Felknor S, Streit J, McDaniel M, Schulte P, Chosewood L, Delclos G, on behalf of workshop participants [2021]. How will the future of work shape OSH research and practice? A workshop summary. Int J Environ Res Public Health 18(11):5696.

Flores E, Xu X, Lu Y [2020]. Human capital 4.0: a workforce competence typology for industry 4.0. Journal of Manufacturing Technology Management 31(4):687-703.

Flynn M [2018]. Immigration, work, and health: anthropology and the occupational health of labor immigrants. Anthropology of Work Review 39(2):116.

Flynn M, Eggerth D [2014]. Occupational health research with immigrant workers. In: Schenker M, Castañeda X, Rodriguez-Lainz A, eds. Migration and health: a research methods handbook. Berkeley: University of California Press.

Flynn M, Eggerth D, Keller B, Check P [2021]. Reaching 'hard to reach' workers: results from a pilot study about approaches to disseminate worker safety information via the Mexican consular network. J Occup Environ Hyg 18(4-5):180-191.

Frey C, Osborne M [2017]. The future of employment: how susceptible are jobs to computerisation? Technol Forecast Soc Change 114:254-280.

Friedland D, Price R [2003]. Underemployment: consequences for the health and well-being of workers. Am J Community Psychol 32(1-2):33-45.

Friedman D, Ellington A [2015]. Industrialization of biology. ACS Synth Biol 4:1053-1055.

Gabriel M, PessI E [2016]. Industry 4.0 and sustainability impacts: critical discussion of sustainability aspects with a special focus on future of work and ecological consequences. Annals of the Faculty of Engineering Hunedoara 14(2):131-136.

Ganster D, Rosen C [2013]. Work stress and employee health: a multidisciplinary review. J Management 39(5):1085-1122.

Guerin R, Castillo D, Hendricks K, Howard J, Piacentino J, Okun A [2020]. Preparing the future workforce for safe and healthy employment. Am J Public Health 110(1):69-71.

Hamilton V [2012]. OECD local economic and employment development (LEED) papers, No. 2012/14. Career pathway and cluster skill development: promising models from the United States. Paris: OECD Publishing, https://dx.doi. org/10.1787/5k94g1s6f7td-en.

Hammer L, Allen S, Leslie J [2021]. Occupational stress and well-being: workplace interventions involving managers/supervisors. In: Lapierre L, Cooper C, eds. Cambridge companion to organisational stress and well-being. Chapter 11. Cambridge, United Kingdom: Cambridge University Press.

Hammer L, Brady J [2021]. Worker well-being and work-life issues. In: Koppes Bryan $\mathrm{L}$, ed. Historical perspectives in industrial and organizational psychology. 2nd ed. London: Routledge/Taylor and Francis Group, pp. 270-291. 
Hammer L, Perry M [2019]. Reducing work-life stress: the place for integrated interventions. In: Hudson H, Nigam J, Sauter S, Chosewood LC, Schill A, Howard J, eds. Total Worker Health. Washington, DC: American Psychological Association, pp. 263-278.

Hammer L, Sauter S [2013]. Total worker health and work-life stress. J Environ Occup Med 55(12):S25-S29.

Handel M [2016]. The O*NET content model: strengths and limitations. J Labour Market Res 49(2):157-176.

Heinrich C [2015]. Federally funded workforce development. Prepared for the Committee on the Supply Chain for Middle-Skill Jobs. NASEM, https://www. nationalacademies.org/our-work/the-supply-chain-for-middle-skill-jobs-educationtraining-and-certification-pathways.

Hines A, Bishop P [2015]. Thinking about the future: guidelines for strategic foresight. 2nd ed. Houston, Texas: Hinesight.

Hirschi A [2018]. The fourth industrial revolution: issues and implications for career research and practice. The Career Development Quarterly 66(3):192-204.

Hollingsworth A, Ruhm C, Simon K [2017]. Macroeconomic conditions and opioid abuse. National Bureau of Economic Research Working Paper Series. National Bureau of Economic Research, https://www.nber.org/papers/w23192.

Holmqvist M [2009]. Corporate social responsibility as corporate social control: the case of worksite health promotion. Scand J Mgmt 25(1):68-72.

Howard J, Murashov V, Branche C [2018]. Unmanned aerial vehicles in construction and worker safety. Am J Ind Med 61(1):3-10.

Howard J, Murashov V, Lowe B, Lu M [2020]. Industrial exoskeletons: need for intervention effectiveness research. Am J Ind Med 63(3):201-208.

Hsiao H [2015]. One size does not fit all. NIOSH science blog, https://blogs.cdc.gov/ niosh-science-blog/2015/09/16/anthropometry/.

ILO [2015]. Definitions: what we mean when we say "economic security." International Labour Organization, https://www.ilo.org/public/english/protection/ ses/download/docs/definition.pdf.

ILO [2019]. Safety and health at the heart of the future of work: building on 100 years of experience. International Labour Organization, https://www.ilo.org/ safework/events/safeday/WCMS_686645/lang--en/index.html.

Institute for the Future [2020]. Future work skills. Palo Alto, CA: Institute for the Future for the University of Phoenix Research Institute, https://www.iftf.org/ uploads/media/SR-1382A_UPRI_future_work_skills_sm.pdf. 
International Federation of Robotics [2019]. Executive summary. World Robotics 2019: industrial robots. Frankfurt, Germany: International Federation of Robotics.

International Organization for Standardization [2012]. Robots and robotic devicesvocabulary. Geneva, Switzerland: International Organization for Standardization.

Jain A, Leka S, Zwetsloot G [2011]. Corporate social responsibility and psychosocial risk management in Europe. J Business Ethics 101(4):619-633.

Jiménez P, Winkler B, Dunkl A [2017]. Creating a healthy working environment with leadership: the concept of health-promoting leadership. Int J Human Resource Mgmt 28(17):2430-2448.

Kahn-Marshall J, Gallant M [2012]. Making healthy behaviors the easy choice for employees: a review of the literature on environmental and policy changes in worksite health promotion. Health Ed Behav 39(6):752-776.

Katz L, Krueger A [2019]. Understanding trends in alternative work arrangements in the United States. Cambridge, MA: National Bureau of Economic Research.

Kitt M, Howard J [2013]. The face of occupational safety and health: 2020 and beyond. Public Health Rep 128(3):138-139.

Kossek E, Lautsch B [2018]. Work-life flexibility for whom? Occupational status and work-life inequality in upper, middle, and lower level jobs. Acad Mgmt Ann 12(1):5-36.

Kretchmer $\mathrm{H}$ [2020]. How drones are helping to battle COVID-19 in Africa-and beyond. World Economic Forum: https://www.weforum.org/agenda/2020/05/ medical-delivery-drones-coronavirus-africa-us/.

LaMontagne A, Keegel T, Louie A, Ostry A, Landsbergis P [2007]. A systematic review of the job-stress intervention evaluation literature, 1990-2005. Int J Occup Environ Health 13(3):268-280.

Lange T [2012]. Job satisfaction and self-employment: autonomy or personality? Small Business Econ 38(2):165-177.

Leigh J, Du J [2012]. Are low wages risk factors for hypertention? Eur J Public Health 22:854-859.

Lowrey A [2018]. Give people money: how a universal basic income would end poverty, revolutionize work, and remake the world. New York: Broadway Books.

Manyika J, Lund S, Chui M, Bughin J, Woetzel J, Batra P, Sanghvi S [2017]. What the future of work will mean for jobs, skills, and wages: jobs lost, jobs gained. McKinskey Global Institute, https://www.mckinsey.com/featured-insights/futureof-work/jobs-lost-jobs-gained-what-the-future-of-work-will-mean-for-jobs-skills-andwages. 
Martin J [2019]. Can Al reduce worker injuries? Dassault Systemes North America, https://blogs.3ds.com/northamerica/can-ai-reduce-worker-injuries/.

McCarthy M [2015]. Beyond the skills gap: making education work for students, employers, and communities. New America Foundation, https://www.newamerica. org/education-policy/policy-papers/beyond-the-skills-gap.

McFall M [2021]. The 'great resignation': an opportunity to rethink employee empowerment. Forbes Business Council, https://www.forbes.com/sites/ forbesbusinesscouncil/2021/08/13/the-great-resignation-an-opportunity-to-rethinkemployee-empowerment/?sh=17f0c05f2e19.

McGee R, Thompson N [2015]. Unemployment and depression among emerging adults in 12 states, behavioral risk factor surveillance system, 2010. Prev Chronic Dis 12(E38):1-11, http://dx.doi.org/10.5888/pcd12.140451.

McKee-Ryan F, Song Z, Wanberg C, Kinicki A [2005]. Psychological and physical wellbeing during unemployment: a meta-analytic study. J Appl Psychol 90(1):53-76.

McKinsey Global Institute [2017]. A future that works: automation, employment and productivity, https://www.mckinsey.com/ /media/mckinsey/featured\%20insights/ Digital\%20Disruption/Harnessing\%20automation\%20for\%20a\%20future $\% 20$ that $\% 20$ works/MGI-A-future-that-works-Executive-summary.ashx.

McNaughton D, Rackensperger T, Dorn D, Wilson N [2014]. Home is at work and work is at home: telework and individuals who use augmentative and alternative communication. Work 48(1):117-126.

McNicholas C, Rhinehart L, Poydock M, Shierholz H, Perez P [2020]. Why unions are good for workers-especially in a crisis like COVID-19. Economic Policy Institute, https://www.epi.org/publication/why-unions-are-good-for-workers-especially-in-acrisis-like-covid-19-12-policies-that-would-boost-worker-rights-safety-and-wages/.

Metz R [2018]. The company embeds microchips in its employees, and they love it. Technology Review, https://www.technologyreview.com/s/611884/this-companyembeds-microchips-in-its-employees-and-they-love-it/.

Mokyr J, Vickers C, Ziebarth N [2015]. The history of technological anxiety and the future of economic growth: is this time different? J Econ Perspectives 29(3):31-50.

Murashov V, Hearl F, Howard J [2016]. Working safely with robot workers:

recommendations for the new workplace. J Occup Environ Hyg 13(3):D61-D71.

Nag A, Mukhopadbyay S [2017]. Wearable flexible sensors: a review. IEEE Sens J 17:3949-3960.

National Academies of Science, Engineering, and Medicine [2015]. Industrialization of biology: a roadmap to accelerate the advanced manufacturing of chemicals. Washington, DC: The National Academies Press. 
National Bureau of Economic Research [2018]. Artificial intelligence, automation and work. By Acemoglu D, Restrepo P. Working paper 24196; doi:10.3386/w24196.

National Public Radio [2021]. As the pandemic recedes millions of workers are saying I quit. NPR, https://www.npr.org/2021/06/24/1007914455/as-the-pandemicrecedes-millions-of-workers-are-saying-i-quit?utm_source=pocket-newtab.

NTSB (National Transportation Safety Board) [2020]. Tesla crash investigation yields 9 NTSB safety recommendations. National Transportation Safety Board News Release, 2/25/2020.

Neuhaus M, Eakin E, Straker L, Owen N, Dunstan D, Reid N, Healy G [2014]. Reducing occupational sedentary time: a systematic review and meta-analysis of evidence on activity-permissive workstations. Obesity Rev 15(10):822-838.

Newman L, Scott J, Childress A, Linnan L, Newhall W, McLellan D, Campo S, Freewynn S, Hammer L, Leff M, Macy G, Maples E, Rogers B, Rohlman D, Tenney L, Watkins C [2020]. Education and training to build capacity in Total Worker Health ${ }^{\circledR}$ : proposed competencies for an emerging field. J Occup Environ Med 62(8):e384e391.

Nielsen K, Taris T, Cox T [2010]. The future of organizational interventions: addressing the challenges of today's organizations. Work \& Stress 24(3):219-233.

NIOSH [2019]. NIOSH strategic plan: FYs 2019-2023. Cincinnati, OH: U.S. Department of Health and Human Services, Centers for Disease Control and Prevention, National Institute for Occupational Safety and Health, https://www.cdc. gov/niosh/about/strategicplan/.

NIOSH [2021a]. NIOSH program portfolio. Cincinnati, OH: U.S. Department of Health and Human Services, Centers for Disease Control and Prevention, National Institute for Occupational Safety and Health, https://www.cdc.gov/niosh/programs/default.html.

NIOSH [2021b]. NIOSH Future of Work Initiative. Cincinnati, OH: U.S. Department of Health and Human Services, Centers for Disease Control and Prevention, National Institute for Occupational Safety and Health, https://www.cdc.gov/niosh/topics/ future-of-work/default.html.

NIOSH [2021c]. Total Worker Health Program. Cincinnati, OH: U.S. Department of Health and Human Services, Centers for Disease Control and Prevention, National Institute for Occupational Safety and Health, https://www.cdc.gov/NIOSH/twh/.

NIOSH, American Society of Safety Professionals [2015]. Overlapping vulnerabilities: the occupational safety and health of young workers in small construction firms. By Flynn M, Cunningham T, Guerin R, Keller B, Chapman LJ, Hudson D et al. Cincinnati, $\mathrm{OH}$ : NIOSH/ASSE, National Institute for Occupational Safety and Health and American Society of Safety Engineers, https://www.cdc.gov/niosh/docs/2015-178/ pdfs/2015-178.pdf?id=10.26616/NIOSHPUB2015178. 
O’Neill T, Hambley L, Greidanus N, MacDonnell R, Kline T [2009]. Predicting teleworker success: an exploration of personality, motivational, situational, and job characteristics. New Technology, Work Employment 24(2):144-162.

O'Connor T, Flynn M, Weinstock D, Zanoni J [2011]. Education and training for underserved populations. Presented at the Eliminating Health and Safety Disparities at Work Conference, Chicago, IL.

Occupational Hygiene Training Association [2021]. Training resources, https://www. ohtatraining.org/training-resources.

OSHA, NIOSH [2015]. Protecting temporary workers. Cincinnati, OH: U.S. Department of Health and Human Services, Centers for Disease Control and Prevention, National Institute for Occupational Safety and Health, https://www.cdc. gov/niosh/docs/2014-139/pdfs/2014-139.pdf?id=10.26616/NIOSHPUB2014139.

Okun A, Guerin R, Schulte P [2016]. Foundational workplace safety and health competencies for the emerging workforce. J Safety Res 59:43-51.

Organisation for Economic Co-operation and Development [2011]. Families are changing. Chapter 1: Doing better for families. Paris: OECD Publishing, pp. 1-53.

Organisation for Economic Co-operation and Development [2016]. Back to work. United States: improving the re-employment prospects of displaced workers. Paris: OECD Publishing, https://www.oecd-ilibrary.org/employment/back-to-work-unitedstates_9789264266513-en.

Palagashvili L, Suarez P [2021]. Women as independent workers in the gig economy. Mercatus working paper series. SSRN, https://ssrn.com/abstract=3815975.

Paul K, Moser K [2009]. Unemployment impairs mental health: meta-analyses. J Vocational Behav 74(3):264-282.

Peckham T, Baker M, Camp J, Kaufman J, Seixas N [2017]. Creating a future for occupational health. Ann Work Expos Health 61(1):3-15.

Perez C [2019]. Invisible women: exposing data bias in a world designed for men. New York: Random House.

Porter M, Kramer M [2011]. Creating shared value. Harvard Bus Rev February, https://hbr.org/2011/01/the-big-idea-creating-shared-value.

Pronk N, Katz A, Lowry M, Payfer J [2012]. Reducing occupational sitting time and improving worker health: the Take-A-Stand Project, 2011. Prev Chronic Dis 9:E154.

Pronk N, Kleinman D, Richmond T [2021]. Healthy People 2030: moving toward equitable health and well-being in the United States. E Clin Med 33:100777.

Quinlan M, Bohle P [2004]. Contingent work and occupational safety. Psychol Workplace Safety 7:81-105. 
Ray T, Kenigsberg T, Pana-Cryan R [2017]. Employment arrangement, job stress, and health-related quality of life. Safety Sci 100:46-56.

Ray T, Pana-Cryan R [2021]. Work flexibility and work-related well-being. Int J Environ Res Public Health 18(6).

Ray T, Sauter S [2012]. Economy and work stress: are they related and how? Perspectives on Work, Labor, and Employment Relations Association 15:854-859.

Rogers W, Kahraman M, Drews F, Powel K, Haight J, Wang Y, Baxla K, Sobalkar M [2019]. Automation in the mining industry: review of technology, systems, human factors, and political risk. Mining, Metallurgy \& Exploration 36:607-631.

Rupp D, Mallory D [2015]. Corporate social responsibility: psychological, personcentric, and progressing. Ann Rev Organ Psychol Organ Behav 2(1):211-236.

Schulte P, Delclos G, Felknor S, Chosewood L [2019]. Toward an expanded focus for occupational safety and health: a commentary. Int J Environ Res Public Health 16(24).

Schulte P, Streit J, Sheriff F, Delclos G, Felknor S, Tamers SL, Fendinger S, Grosch $J$, Sala R [2020]. Potential scenarios and hazards in the work of the future: a systematic review of the peer-reviewed and gray literatures. Ann Work Expos Health 64(8):786-816.

Schur L, Ameri M, Kruse D [2020]. Telework after COVID: a "silver lining" for workers with disabilities? J Occup Rehab 30:521-536.

Siekmann G, Fowler C [2017]. Identifying work skills: international approaches. National Centre for Vocational Education Research, https://files.eric.ed.gov/fulltext/ ED579874.pdf.

Sinclair R, Allen T, Barber L, Bergman M, Britt T, Butler A, Ford M, Hammer L, Kath L, Probst T, Yuan Z [2020]. Occupational health science in the time of COVID-19: now more than ever. Editorial/commentary. Occup Health Sci 4:1-22.

Skills Framework for the Information Age [2000]. The global skills and competency framework for a digital world. SFIA, https://www.sfia-online.org/en.

Skills Future [2016]. Singapore's skills framework. Skills Future, https://www. skillsfuture.gov.sg/skills-framework.

Soujourner A, Yang J [2020]. Effects of union certification on workplace-safety enforcement: regression-discontinuity evidence. ILR Rev (epub ahead of print).

Souza K, Steege A, Baron S [2010]. Surveillance of occupational health disparities: challenges and opportunities. Am J Ind Med 53(2):84-94.

Streit J, Felknor S, Edwards N, Howard J [2021]. Leveraging strategic foresight to advance worker safety, health, and well-being. Int J Environ Res Public Health 18(16):8477. 
Tamers SL, Streit J, Pana-Cryan R, Ray T, Syron L, Flynn M, Castillo D, Roth G, Geraci C, Guerin R, Schulte P, Henn S, Chang C, Felknor S, Howard J [2020]. Envisioning the future of work to safeguard the safety, health, and well-being of the workforce: a perspective from the CDC's National Institute for Occupational Safety and Health. Am J Ind Med 63(12):1065-1084.

The President's Council of Advisors on Science and Technology [2020]. Recommendations for strengthening American leadership in industries of the future. PCAST, https://science.osti.gov/-/media/_/pdf/about/pcast/202006/PCAST_June_2020_ Report.pdf?la=en\&hash=019A4F17C79FDEE5005C51D3D6CAC81FB31E3ABC.

Theodossiou I [1998]. The effects of low-pay and unemployment on psychological well-being: a logistic regression approach. J Health Econ 17(1):85-104.

Toch M, Bambra C, Lunau T, Van der Wel K, Witvliet M, Dragano N, Eikemo T [2014]. All part of the job? The contribution of the psychosocial and physical work environment to health inequalities in Europe and the European health divide. Int $\mathrm{J}$ Health Services 44(2):285-305.

Tomczak D, Behrend T, Willford J, Jimenez W [2020]. I didn't agree to these terms: electronic performance monitoring violates the psychological contract. PsyArXiv, https://psyarxiv.com/qax9u/.

Toosi M [2013]. Labor force projections in 2024. Monthly Labor Rev, 1-27.

Toxiri S, Näf M, Lazzaroni M, Fernández J, Sposito M, Poliero T, Monica L, Anastasi S, Caldwell D, Ortiz J [2019]. Back-support exoskeletons for occupational use: an overview of technological advances and trends. IISE Transactions on Occupational Ergonomics and Human Factors 7(3-4):237-249.

Vermeulen B, Kesselhut J, Pyka A, Saviotti P [2018]. The impact of automation on employment: just the usual structural change? Sustainability 10(5):1661.

Vietas $\mathrm{J}$ [2021]. The role of artificial intelligence in the future of work. NIOSH Science Blog, https://blogs.cdc.gov/niosh-science-blog/2021/05/24/ai-future-of-work/.

West D, Allen J [2018]. How artificial intelligence is transforming the world. Washington, DC: Brookings Institute, https://www.brookings.edu/research/howartificial-intelligence-is-transforming-the-world/.

World Economic Forum [2016]. The future of jobs: employment, skills, and workforce strategy for the fourth industrial revolution. Geneva: World Economic Forum.

World Economic Forum [2020]. The future of jobs report, 2020. World Economic Forum, https://www.weforum.org/reports/the-future-of-jobs-report-2020.

World Health Organization [2020]. Occupational health: stress at the workplace. Geneva: World Health Organization, https://www.who.int/news-room/q-a-detail/ ccupational-health-stress-at-the-workplace. 
Zoorob M [2018]. Does 'right to work' imperil the right to health? The effect of labour unions on workplace fatalities. Occup Environ Med 75(10):736-738.

Zou J, Schiebinger L [2018]. Al can be sexist and racist. It's time to make it fair. Nature 559(7714):324-326. 


\section{NiosH}

Promoting productive workplaces through safety and health research

DHHS (NIOSH) Publication No. 2022-105

DOI: https://doi.org/10.26616/NIOSHPUB2022105

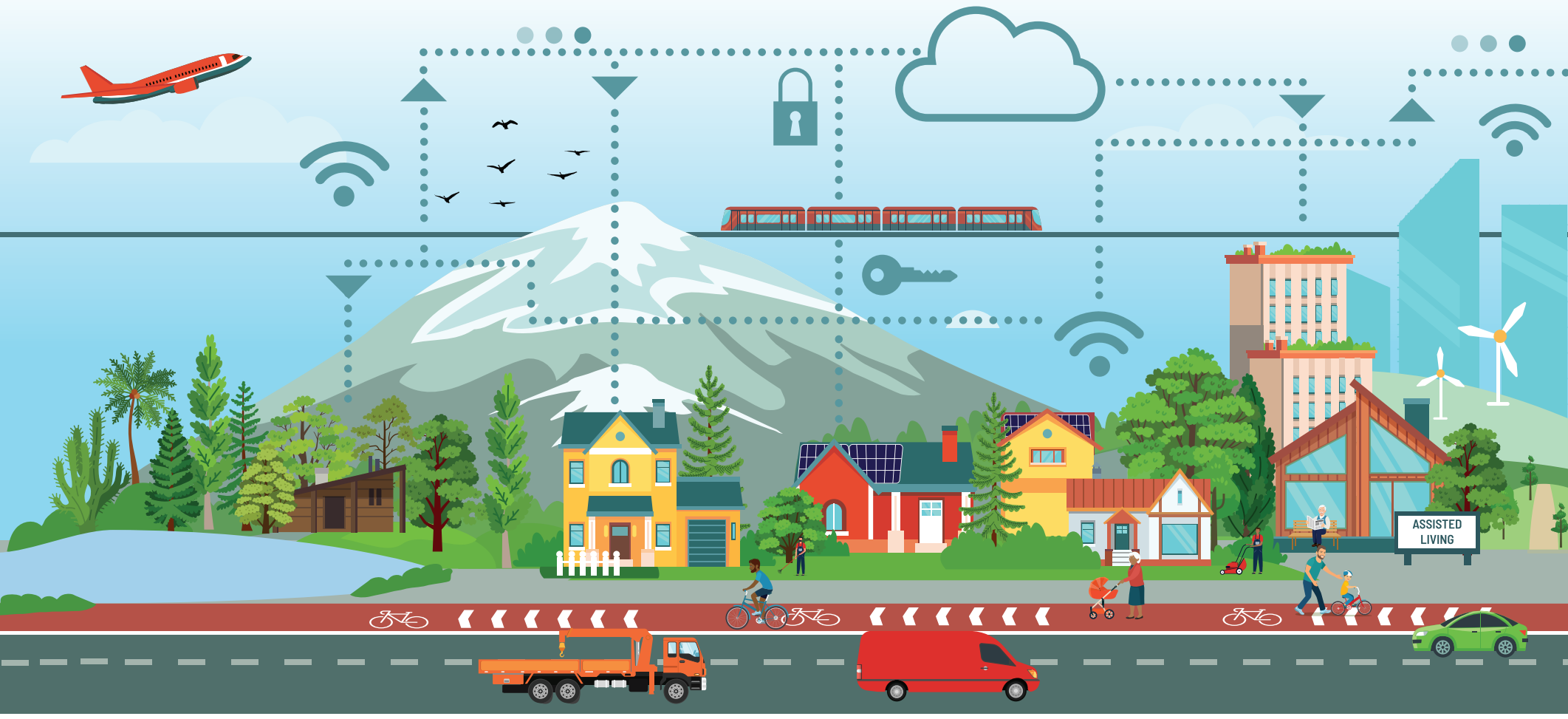

